OPEN ACCESS

Edited by:

Lisa F. P. Ng,

Singapore Immunology Network

(A*STAR), Singapore

Reviewed by:

Juan Pablo Jaworski,

National Council for Scientific and

Technical Research

(CONICET), Argentina

Peter Liljeström

Karolinska Institutet (KI), Sweden

${ }^{*}$ Correspondence:

Daniel N. Streblow

streblow@ohsu.edu

tPresent address: Rebecca M. Broeckel and

Daniel N. Streblow,

Rocky Mountain Laboratories,

NIH/NIAID, Hamilton, MT,

United States

Specialty section:

This article was submitted to

Viral Immunology,

a section of the journal

Frontiers in Immunology

Received: 07 August 2019 Accepted: 16 October 2019

Published: 31 October 2019

Citation:

Broeckel RM, Haese N, Ando T, Dmitriev I, Kreklywich CN, Powers J,

Denton M, Smith P, Morrison TE, Heise M, DeFilippis V, Messaoudi I, Curiel DT and Streblow DN (2019) Vaccine-Induced Skewing of T Cell

Responses Protects Against

Chikungunya Virus Disease.

Front. Immunol. 10:2563.

doi: 10.3389/fimmu.2019.02563

\title{
Vaccine-Induced Skewing of T Cell Responses Protects Against Chikungunya Virus Disease
}

\author{
Rebecca M. Broeckel ${ }^{1 \dagger}$, Nicole Haese ${ }^{1}$, Takeshi Ando ${ }^{1}$, Igor Dmitriev ${ }^{2}$, \\ Craig N. Kreklywich ${ }^{1}$, John Powers ${ }^{1}$, Michael Denton ${ }^{1}$, Patricia Smith ${ }^{1}$, \\ Thomas E. Morrison ${ }^{3}$, Mark Heise ${ }^{4,5}$, Victor DeFilippis ${ }^{1}$, Ilhem Messaoudi ${ }^{6}$, \\ David T. Curiel ${ }^{2}$ and Daniel N. Streblow ${ }^{1,7 * t}$
}

\begin{abstract}
${ }^{1}$ Vaccine and Gene Therapy Institute, Oregon Health and Science University, Beaverton, OR, United States, ${ }^{2}$ Department of Radiation Oncology, Washington University, St. Louis, MO, United States, ${ }^{3}$ Department of Immunology and Microbiology, University of Colorado School of Medicine, Aurora, CO, United States, ${ }^{4}$ Department of Genetics, The University of North Carolina at Chapel Hill, Chapel Hill, NC, United States, ${ }^{5}$ Department of Microbiology and Immunology, The University of North Carolina at Chapel Hill, Chapel Hill, NC, United States, ${ }^{6}$ Department of Molecular Biology and Biochemistry, University of California, Irvine, Irvine, CA, United States, ${ }^{7}$ Division of Pathobiology and Immunology, Oregon National Primate Research Center, Beaverton, OR, United States
\end{abstract}

Chikungunya virus (CHIKV) infections can cause severe and debilitating joint and muscular pain that can be long lasting. Current CHIKV vaccines under development rely on the generation of neutralizing antibodies for protection; however, the role of $T$ cells in controlling CHIKV infection and disease is still unclear. Using an overlapping peptide library, we identified the CHIKV-specific $T$ cell receptor epitopes recognized in C57BL/6 infected mice at 7 and 14 days post-infection. A fusion protein containing peptides 451, 416, a small region of nsP4, peptide 47, and an HA tag (CHKVf5) was expressed using adenovirus and cytomegalovirus-vectored vaccines. Mice vaccinated with $\mathrm{CHKV} f 5$ elicited robust $\mathrm{T}$ cell responses to higher levels than normally observed following CHIKV infection, but the vaccine vectors did not elicit neutralizing antibodies. CHKVf5-vaccinated mice had significantly reduced infectious viral load when challenged by intramuscular $\mathrm{CHIKV}$ injection. Depletion of both $\mathrm{CD}^{+}{ }^{+}$and $\mathrm{CD} 8^{+} \mathrm{T}$ cells in vaccinated mice rendered them fully susceptible to intramuscular CHIKV challenge. Depletion of $\mathrm{CD}^{+} \mathrm{T}$ cells alone reduced vaccine efficacy, albeit to a lesser extent, but depletion of only $\mathrm{CD} 4^{+} \mathrm{T}$ cells did not reverse the protective phenotype. These data demonstrated a protective role for $\mathrm{CD}^{+}{ }^{+} \mathrm{T}$ cells in $\mathrm{CHIKV}$ infection. However, CHKVf5-vaccinated mice that were challenged by footpad inoculation demonstrated equal viral loads and increased footpad swelling at $3 \mathrm{dpi}$, which we attributed to the presence of CD4T cell receptor epitopes present in the vaccine. Indeed, vaccination of mice with vectors expressing only $\mathrm{CHIKV}$-specific $\mathrm{CD}^{+}{ }^{+} \mathrm{T}$ cell epitopes followed by $\mathrm{CHIKV}$ challenge in the footpad prevented footpad swelling and reduced proinflammatory cytokine and chemokines associated with disease, indicating that $\mathrm{CHIKV}$-specific $\mathrm{CD}^{+}{ }^{+} \mathrm{T}$ cells prevent $\mathrm{CHIKV}$ disease. These results also indicate that a $\mathrm{T}$ cell-biased prophylactic vaccination approach is effective against $\mathrm{CHIKV}$ challenge and reduces $\mathrm{CHIKV}$-induced disease in mice.

Keywords: Chikungunya virus (CHIKV), vaccine, T cell, pathogenesis, cytokine 


\section{INTRODUCTION}

Chikungunya virus (CHIKV) is a mosquito-transmitted virus that causes fever, rash, and debilitating joint and muscle pain in humans. Though the fever and rash resolve, joint and muscle pain can be long lasting. According to some studies, up to $75 \%$ of CHIKV-infected patients experience chronic arthritic and muscle pain for months to years following resolution of the acute disease (1-3). The consequences of chronic joint pain are significant, with patients reporting limited mobility, depression, and decreased quality of life (4). CHIKV can rapidly spread and cause disease in millions of people in a short period of time, as illustrated by recent epidemics in the Indian Ocean region (2004-2011) and the Americas (2013-2015) (5-7). Since no FDA-approved vaccines or antivirals exist for CHIKV, research into prophylactic and therapeutic interventions are highly warranted. The protective role for anti-CHIKV neutralizing antibodies has been well-established in both mouse and nonhuman primate models (8-11). Potent neutralizing antibodies can provide sterilizing immunity if administered prophylactically or if derived through vaccination. However, after the first few days of infection, neutralizing antibodies may have limited efficacy to clear virus from infected tissues (9), suggesting other immune components, such as $\mathrm{T}$ cells, could be involved in viral clearance of persistent joint-localized CHIKV.

CHIKV vaccine candidates under development elicit both humoral and cellular responses to CHIKV antigens. CHIKV vaccines currently being pursued in clinical trials cover a wide range of platforms including virus-like particle (VLP), liveattenuated, viral-vectored, and mRNA-based vaccines (12-16). Vaccine-elicited neutralizing antibodies are the key to protection against CHIKV, but the direct contribution of vaccine-induced $\mathrm{T}$ cells in protection against CHIKV is rarely characterized. Two preclinical vaccines, the live-attenuated CHIKV/IRES vaccine and the modified vaccinia virus Ankara (MVA) vectored vaccine, assessed the impact of vaccine-induced T cells (1720). Both vaccines elicited humoral and cellular responses against CHIKV antigens. However, in the context of vaccineinduced neutralizing antibodies, the roll of cellular immunity appears minimal. In fact, $T$ cell depletion of CHIKV/IRESvaccinated A129 mice or adoptive transfer of immune $\mathrm{CD} 4^{+}$ or $\mathrm{CD}^{+}{ }^{\mathrm{T}}$ cells did not protect A129 mice from CHIKV (18). However, a modified vaccinia virus ankara (MVA) vaccine vector that expresses $\mathrm{E} 3 / \mathrm{E} 2$ was shown to require $\mathrm{CD} 4^{+} \mathrm{T}$ cells for protection since $\mathrm{CD} 4^{+} \mathrm{T}$ cell depletion increased susceptibility to CHIKV challenge (20). While low levels of E2 neutralizing antibodies were identified following vaccination that may have

\footnotetext{
Abbreviations: CHIKV, Chikungunya virus; RRV, Ross River virus; SINV, Sindbis virus; VEEV, Venezquelan equine encephalitis virus; MCMV, mouse cytomegalovirus; AdV, Adenovirus 5; ELISA, enzyme-linked immunosorbent assay; ELISpot, enzyme-linked immune adsorben spot; MIP-1 $\alpha$, macrophage inflammatory protein-1alpha; MIP-2, macrophage inflammatory protein-2; MCP1 , monocyte chemoattractant protein-1; M-CSF, macrophage colony stimulating factor; IL-12, interleukin 12; RANTES, regulated upon activation, normal T cell expressed, and secreted; CNS, central nervous system; CTLA4, cytotoxic Tlymphocyte-associated protein 4; MHC, major histocompatibility antigen; HLA$\mathrm{DR}$, human leukocyte antigen DR isotype.
}

contributed to the protection seen in A129 mice, a role for direct cellular immunity or $\mathrm{CD} 8^{+} \mathrm{T}$ cells was not shown.

$\mathrm{CD}^{+} \mathrm{T}$ cells have been implicated as a major contributor to joint inflammation during CHIKV infection of mice. Footpad injection of C57BL/6 mice with CHIKV results in edema, arthritis, and tenosynovitis in the ankle joint, as well as necrosis in the musculoskeletal tissues (21). Infiltrating cells in the ankle include $\mathrm{CD} 4^{+}$and $\mathrm{CD} 8^{+} \mathrm{T}$ cells, macrophages, neutrophils, and natural killer cells (21). Mice lacking $\mathrm{CD}^{+}{ }^{+} \mathrm{T}$ cells have reduced inflammation of the footpad after infection, but viral levels in the blood and ankle are similar to control mice (22). Adoptive transfer of CHIKV-specific $\mathrm{CD} 4^{+} \mathrm{T}$ cells into $\mathrm{TCR}^{-/-}$mice also resulted in increased footpad swelling and joint vascular leakage compared to controls after CHIKV infection, while viral load in the blood remained the same as controls (23). Furthermore, therapeutic administration of mice with CTLA4-Ig after CHIKV infection inhibited $\mathrm{T}$ cell recruitment to the ankle and decreased footpad swelling (24). In contrast to $\mathrm{CD} 4^{+} \mathrm{T}$ cells, depletion of $\mathrm{CD}^{+} \mathrm{T}$ cells fails to reduce footpad swelling (22). This data supports a pathogenic role for $\mathrm{CD} 4^{+} \mathrm{T}$ cells but the role for $\mathrm{CD}^{+} \mathrm{T}$ cells remains unclear. Some evidence suggest $\mathrm{T}$ cells promote viral clearance during CHIKV infection. Mice lacking B and $\mathrm{T}$ cells $\left(\mathrm{Rag}_{1}{ }^{-/}\right.$or $\mathrm{Rag} 2^{-/-}$) develop more severe persistent infections characterized by chronic viremia and persistence of infectious virus in a number of tissues $(9,25)$. Passive transfer of neutralizing antibodies into Rag $1^{-/}$mice fails to clear CHIKV in tissues of persistently infected animals (9). In addition, mice lacking mature B cells ( $\mu \mathrm{MT}$ mice) vaccinated with an inactivated CHIKV vaccine have decreased levels of virus in the serum compared to control-vaccinated mice after CHIKV challenge, although the vaccinated mice also had increased footpad swelling (25). This suggests that vaccine-elicited $\mathrm{T}$ cells can provide limited protection, but this was not directly tested. Combined, these data are suggestive of a role of cellular immunity in protection against $\mathrm{CHIKV}$ infection.

Antiviral $\mathrm{CD} 8^{+} \mathrm{T}$ cells have been shown to be important for reducing viral loads and disease for other alphavirus infections. Depletion of CD8 ${ }^{+} \mathrm{T}$ cells in Ross River virus (RRV) infected mice at 7 and 12 dpi increased levels of RRV RNA in the quadriceps at $14 \mathrm{dpi}$ (26). Similarly, infection of $\mathrm{CD} 8 \alpha^{-/-}$ mice with RRV results in increased levels of RRV RNA in the quadriceps at 14 and $21 \mathrm{dpi}$, but equal levels of virus is detected in the ankle, compared to wild type mice. $\mathrm{T}$ cells have also been implicated in protection against Sindbis virus (SINV) infiltration into the CNS (27), and $\mathrm{CD}^{+}{ }^{+} \mathrm{T}$ cells may protect against Venezuelan Equine Encephalitis virus (VEEV) -induced encephalitis in mice (28).

In the current study, we utilized murine cytomegalovirus (MCMV) and adenovirus (AdV) vaccine vectors as tools to investigate the role for antiviral $\mathrm{CD} 4^{+}$and $\mathrm{CD}^{+}{ }^{+} \mathrm{T}$ cells during CHIKV infection. We profiled $\mathrm{T}$ cell epitopes recognized in CHIKV mice using a complete CHIKV (22) overlapping peptide library. Based upon the results from this screen, we generated a CHIKV fusion gene called CHIKVf5 that encodes several peptides that elicited T cell IFN $\gamma$ responses. The fusion gene was recombined into MCMV and AdV vaccine vectors to elicit $\mathrm{CD}^{+}$and $\mathrm{CD}^{+}{ }^{+} \mathrm{T}$ cell responses in mice. After vaccination, 
we observed earlier joint inflammation in mice challenged in the footpad. However, mice challenged intramuscularly had significant reduction of viral loads in leg muscle tissue. T cell depletion experiments demonstrated that $\mathrm{CD}^{+}{ }^{+} \mathrm{T}$ cells were essential for protection in the muscle tissue. Mice vaccinated with $\mathrm{CD}^{+} \mathrm{T}$ cell epitopes showed decreased CHIKV-induced joint swelling after footpad challenge. This study describes a protective role for $\mathrm{CD}^{+} \mathrm{T}$ cells in $\mathrm{CHIKV}$ infection and disease.

\section{MATERIALS AND METHODS}

\section{Cells}

Vero cells, mouse embryonic fibroblasts (NIH/3T3), and 293IQ cells [HEK293 cells expressing the lac repressor (29)] were propagated at $37^{\circ} \mathrm{C}$ with $5 \% \mathrm{CO}_{2}$ in Dulbecco's Modified Eagle Medium (DMEM) supplemented with 5 or $10 \%$ Fetal Bovine Serum (FBS) and Penicillin-Streptomycin-L-Glutamine (PSG). Aedes albopictus cells (C6/36s) were propagated at $28^{\circ} \mathrm{C}$ with $5 \%$ $\mathrm{CO}_{2}$ in DMEM supplemented with $10 \% \mathrm{FBS}$ and PSG.

\section{Viruses}

CHIKV SL15649 and CHIKV 181/25 was generated from the infectious clones. Briefly, the infectious clone was digested with NotI, and DNA was purified with the QIAquick PCR purification kit (Qiagen) according to the manufacturer's instructions. Viral mRNA was generated with the mMESSAGE mMACHINE SP6 Transcription Kit (ThermoFisher), and the mRNA was purified using the RNeasy Mini Kit (Qiagen). Roughly $3 \mu \mathrm{g}$ RNA was transfected into Vero cells using Lipofectamine 2000 (ThermoFisher). CHIKV virus stocks were passaged once C6/36 cells for $72 \mathrm{~h}$, and viral stocks were prepared by ultracentrifugation over a 15\% sucrose cushion (SW 32 Ti Rotor, $1 \mathrm{~h} 10 \mathrm{~min}, 76,755 \times \mathrm{g}$ ). The virus pellets were resuspended in PBS and aliquots were stored at $-80^{\circ} \mathrm{C}$. For CHIKV limiting dilution plaque assays, 10-fold serial dilutions of virus stocks or tissue homogenates were plated on Vero cells. The cells were placed on a rocker in an incubator at $37^{\circ} \mathrm{C}$ with $5 \% \mathrm{CO}_{2}$ for $2 \mathrm{~h}$, and DMEM containing $0.3 \%$ high viscosity carboxymethyl cellulose (CMC) (Sigma) and 0.3\% low viscosity CMC (Sigma) was added to the cells. After 2 days, cells were fixed with $3.7 \%$ formaldehyde (Fisher), stained with $0.5 \%$ methylene blue (Fisher), and dried. Plaques were enumerated under a light microscope.

\section{Vectors}

The Smith strain MCMV bacterial artificial chromosome (BAC) pSMfr3 (30) was utilized for generating infectious MCMV vaccines. The gene of interest was inserted in-frame onto the C-terminus of the MCMV IE2 gene so that the insertion is co-expressed with IE2 (31). Generation of the MCMV constructs was performed via a two-step galactokinase/kanamycin (GalK/Kan) cassette insertion and replacement $(32,33)$. The GalK/Kan cassette was generated by PCR with primers that overlapped ie2 by $50 \mathrm{bp}$. The PCR product was electroporated into electrocompetent SW105 cells containing pSMfr3, and bacteria were selected on Kan-containing agarose plates. The fusion gene CHKVf5 was generated by overlapping PCR. A PCR product containing 50 bp homology with ie2 was generated (F primer: GGTTCTTTCTCTTGACCAGAGACCTGGTGACCG TCAGGAAGAAGATTCAGTGTGCGGTGCATTCGATGAC, R primer: AACCTCTTTATTTATTGATTAAAAACCATGACA TACCTCGTGTCCTCTCAGGCGTAGTCGGGCACATC) and electroporated into SW105 cells containing the IE2-GalK/Kan MCMV BAC. Resulting bacteria were selected on 2-deoxygalactose (DOG) minimal plates, and the presence of the insert was confirmed by PCR and sequencing. Virus was reconstituted by electroporation into NIH/3T3 cells, and passaged five times to eliminate the BAC cassette prior to ultracentrifugation. Constructs were screened by PCR and sequenced to confirm the presence of the insert. MCMVs were titered by plaque assays on NIH/3T3s. Dilutions of virus was plated on NIH/3T3s, and cells were placed in an incubator on a rocker. At $2 \mathrm{hpi}$, a CMC overlay was added to the cells, and the cells were incubated for 5-7 days, until plaques were formed, prior to fixing and staining with methylene blue.

\section{Adenovirus Vectors}

Replication-defective human Ad5 adenoviruses (del E1, E3) were generated using the AdMax HiIQ system (Microbix). Genes of interest were cloned into the shuttle plasmid pDC316(io) and cotransfected with pBHGlox $\Delta \mathrm{E} 1,3 \mathrm{Cre}$ plasmid into 293 IQ cells to reconstitute virus as previously described $(29,34)$. Transfections were performed using the PureFection kit (System Biosciences) according to the manufacturer's protocol, and adenovirus plaques were observed after 10-14 days in cell culture. Viruses were passaged four times in 293 IQ cells prior to ultracentrifugation. Constructs were screened by PCR and sequenced to confirm the presence of the insert. Adenovirus titers were calculated using limiting dilution assays on 293 IQs in 96-well plates.

\section{Mouse Experiments}

All mouse experiments were performed at OHSU in ABSL3 laboratories in compliance with OHSU IACUC protocols. The small lab animal unit at OHSU is accredited by the Association for the Accreditation and Assessment of Laboratory Animal Care (AALAC) International. Animals were housed in ventilated racks and monitored daily by veterinary staff. C57BL/6J mice were vaccinated as indicated with MCMV delivered intraperitoneally ( $10^{6}$ PFU, i.p.), and/or AdV injected intramuscularly in the thigh ( $10^{8}$ PFU, i.m.). Mice were challenged with $10^{3}$ PFU CHIKV in a $20 \mu \mathrm{l}$ volume in the footpad (f.p.), or they were challenged (i.m.) with $10^{3}$ or $10^{4} \mathrm{PFU}$ in a $20 \mu$ l volume in the calf muscle. Footpad measurements were taken with calipers. For $\mathrm{T}$ cell depletion experiments, mice were administered $\mathrm{T}$ cell depleting antibodies diluted in PBS in a $100 \mu \mathrm{l}$ volume (i.p.). Vaccinated groups were injected with $300 \mu \mathrm{g}$ anti-CD4 (GK1.5, BioXCell), $300 \mu \mathrm{g}$ anti-CD8 (2.43, BioXCell), $300 \mu \mathrm{g}$ Rat IgG2b Isotype Control (LTF-2, BioXCell), or a combination of $300 \mu \mathrm{g}$ anti-CD4 and $300 \mu \mathrm{g}$ anti-CD8. T cell depletions were confirmed by flow cytometry. To confirm T cell depletions, splenocytes were stained with fluorophore-conjugated antibodies specific for mouse CD3, CD4, CD8, and CD19. Fluorescent markers were detected on an LSRII instrument (BD Pharminogen) and data was analyzed using FlowJo (TreeStar). 


\section{Western Blot Analysis}

$\mathrm{NIH} / 3 \mathrm{~T} 3$ cells were left uninfected or infected with MCMV CHKVf5 or AdV CHKVf5. Cells were lysed in $1 \times$ Cell Lysis buffer (Cell Signaling) supplemented with $1 \mathrm{mM}$ Phenylmethylsulfonyl fluride (PMSF) (Fisher), scraped, and incubated on ice for $15 \mathrm{~min}$. Lysates were centrifuged $\left(4^{\circ} \mathrm{C}, 10 \mathrm{~min}, 16,000 \times \mathrm{g}\right)$, and supernatants were transferred to a new tube containing Laemmli buffer. Samples were boiled $10 \mathrm{~min}$ and loaded onto $4-12 \%$ BisTris SDS-PAGE gels (Thermo/Fisher). Samples were transferred onto Immobilon-P Transfer Membranes (Fisher). Membranes were blocked in 5\% milk powder in Tris-buffered saline supplemented with $0.1 \%$ Tween 20 (TBST), and membranes were probed with anti-HA antibody (Roche, clone 3F10) at 1:1,000 dilution followed by rabbit anti-Rat HRP-conjugated secondary antibody or anti-GAPDH-HRP (Cell Signaling) for a loading control. Blots were washed with TBST, and the membrane was incubated with chemiluminescent substrate to visualize the bands. The membrane was exposed with X-ray film.

\section{Neutralization Assays}

Blood samples were collected and left at room temperature for $30 \mathrm{~min}$ to allow for clotting. Blood was centrifuged (5 min, $3,000 \times \mathrm{g}$ ) and sera was transferred to a new tube. Sera was heatinactivated at $56^{\circ} \mathrm{C}$ for $30 \mathrm{~min}$. Following heat-inactivation, sera was serially diluted in DMEM supplemented with 5\% FBS and PSG. Roughly 100 plaque forming units of CHIKV 181/25 were added to serum dilutions, and the complexes were incubated at $37^{\circ} \mathrm{C}$ for $2 \mathrm{~h}$. Following incubation, complexes were added to Vero cells and placed on a rocker for $2 \mathrm{~h}$ at $37^{\circ} \mathrm{C}$. CMCcontaining media was added to the cells, and cells were placed in a $37^{\circ} \mathrm{C}$ incubator for 2 days prior to fixing and staining.

\section{ELISpot Assays}

ELISpot assays were performed as previously described (35). Briefly, a single cell splenocyte suspension was prepared by pushing whole spleen through a $70 \mu \mathrm{m}$ cell strainer and rinsing with $15 \mathrm{ml}$ RMPI complete media (10\% FBS, PSG). Cells were pelleted $(10 \mathrm{~min}$ at $650 \times \mathrm{g})$, and red blood cells were lysed with $1 \times$ Red Blood Cell Lysis Buffer (Bioleged) for 3 min. Splenocytes were replenished with $10 \mathrm{ml}$ RMPI complete and pelleted as before. Cells were resuspended into $5 \mathrm{ml}$ RPMI complete, counted, and samples were normalized to cell count. Splenocytes were added to prewashed Mouse IFN $\gamma$ ELISpot plates (MabTech) with $1 \mu \mathrm{l}$ peptide (10 $\mu \mathrm{g} /$ well), $1 \mu \mathrm{l}$ DMSO, or $1 \mu \mathrm{l}$ of phorbol 12-myristate 13-acetate/Ionomycin stock as a positive control. Splenocytes were incubated on ELISpot plates for 24-48 h. Plates were washed and incubated with anti-mouse IFN $\gamma$ biotin antibody for $2 \mathrm{~h}$ and streptavidin-ALP antibody for $1 \mathrm{~h}$ according to the manufacturer's protocol. Spots were visualized using BCIP/NPT-plus substrate, and plates were rinsed with water and dried prior to counting with an AID ELISPot plate reader.

\section{Mouse Cytokine Multiplex Assay}

A Milliplex MAP Mouse Cytokine Magnetic Bead Panel multiplex assay (Millipore Sigma) was used to quantify the protein levels for 26 cytokines, chemokines, and growth factors in ankle tissues from vaccinated and control mice at 8 days post footpad challenge with CHIKV. Entire ankle samples were homogenized in PBS with $2 \mathrm{~mm}$ beads (Propper Manufacturing Co., Inc.) using a Precellys 24 homogenizer (Precellys Bertin Technologies). Cellular debris was pelleted by centrifugation at $5,000 \times \mathrm{g}$ for $2 \mathrm{~min}$, and the supernatants were transferred to a new $1.7 \mathrm{ml}$ tube. For the assay, washed antibody-conjugated polystyrene magnetic beads were incubated with a seven-point standard curve or $25 \mu \mathrm{l}$ of ankle tissue homogenate plus $25 \mu \mathrm{l}$ of blocking buffer. Samples were incubated at room temperature in the dark for $2 \mathrm{~h}$, washed and then labeled with biotinylated detector antibody for $1 \mathrm{~h}$. Following washing with blocking buffer, the beads were incubated with Phycoerythrin-conjugated streptavidin for $30 \mathrm{~min}$ and then washed. Cytokines were quantified using a Luminex $200^{\mathrm{TM}}$ Detection system (Luminex), and the data was analyzed and graphed using GraphPad Prism v6 software.

\section{RESULTS}

\section{Identification of CHIKV T Cell Epitopes in C57BL/6 Mice}

Few dominant CHIKV T cell epitopes have been experimentally described in C57BL/6 mice $(23,36)$. To identify T cell epitopes recognized during $\mathrm{CHIKV}$ infection of $\mathrm{C} 57 \mathrm{BL} / 6$ mice, we screened $\mathrm{T}$ cell responses by IFN $\gamma$ ELISpot using a CHIKV 18 mer peptide library with 10 amino acid overlap. For this assay, splenocytes were isolated and pooled from three mice infected with CHIKV for 7 or 14 days (Figure 1A) and cultured on 96-well ELISpot plates for 2 days in the presence of peptides, negative control peptides, or PMA/ionomycin (positive control). Plates were washed and stained for IFN $\gamma$. The stained wells were scanned and spots were enumerated. We identified several CHIKV peptides that elicited an IFN $\gamma$ response that mapped to nsP1, E2, and E1. In addition, we observed a wider breadth of $\mathrm{T}$ cell IFN $\gamma$ responses at $7 \mathrm{dpi}$ (26 peptides recognized) that became more refined at $14 \mathrm{dpi}$ (15 peptides). The screen was repeated (Figure 1B), validating the peptides eliciting the strongest responses as peptides 47, 256, 350, 439, and 451. Peptides 451 (CAVHSMTNAVTIREAEIE) and 350 (DNFNVYKATRPYLAHCPD) were previously shown to elicit T cell responses, providing further validation of our assay $(23,36)$. Table 1 lists all of the peptides that consistently elicited an IFN $\gamma$ response above background.

\section{Generation of MCMV and AdV-Vectored Vaccines Directed Against CHIKV}

A fusion polypeptide (CHKVf5) was constructed containing two peptides that elicited strong IFN $\gamma$ responses (peptide 47 and 451) with a small region of nsP4 (aa 167-475) that was predicted in silico to contain several $\mathrm{H} 2-\mathrm{Db}$ restricted $\mathrm{T}$ cell epitopes (37). We identified a dominant epitope in peptide 256 in this region of nsP4. Peptide 416 (E1), a peptide that consistently failed to induce IFN $\gamma$ response by ELISPOT in splenocytes from CHIKVinfected mice, was included as a control peptide (Figure 2A). The CHIKVf5 fusion protein also contained an in-frame $\mathrm{C}^{\prime}$ terminal 

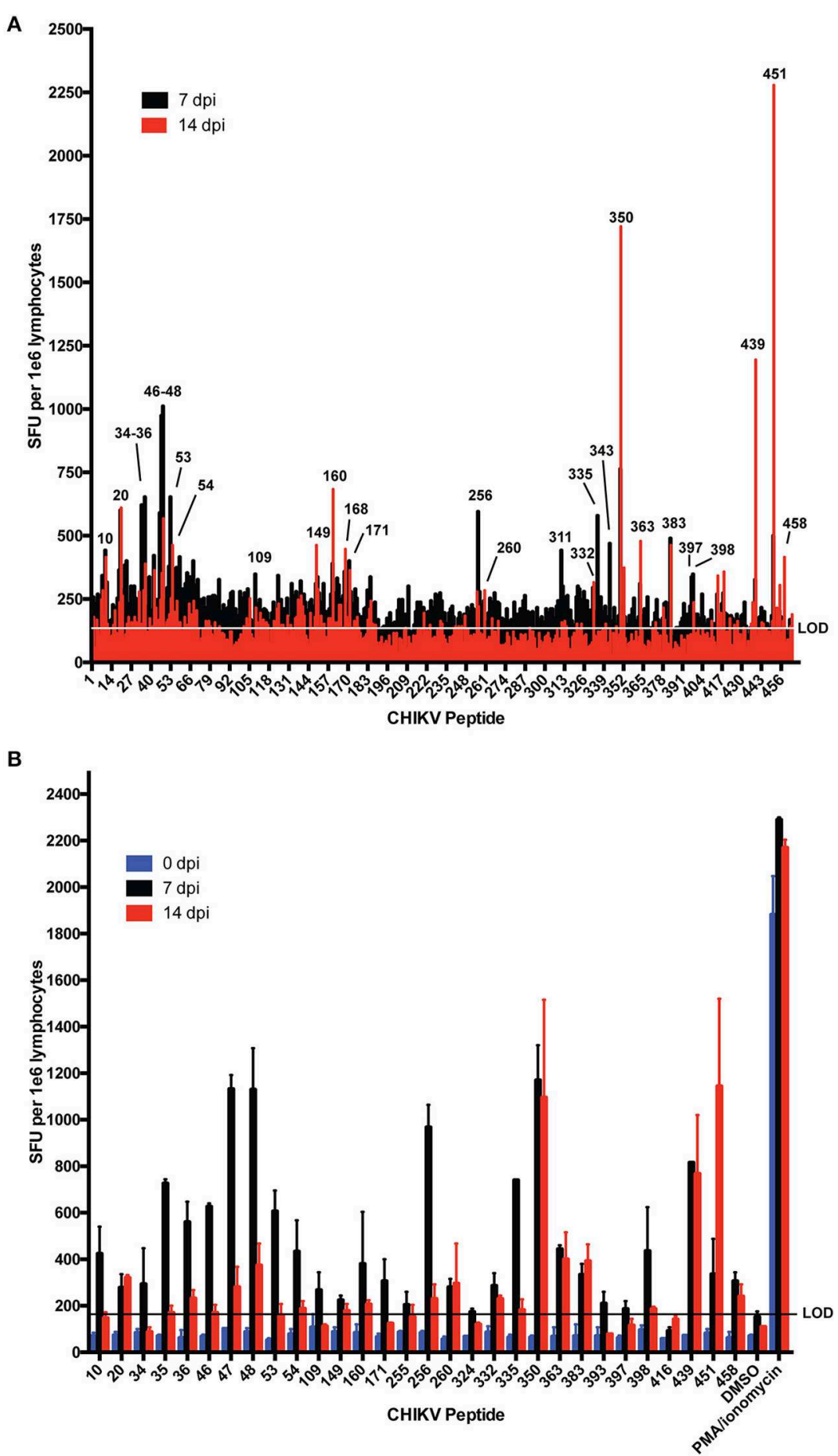

FIGURE 1 | IFN $\gamma$ responses in C57BL/6 mice at 7 and 14 days post CHIKV infection. Mice were infected with 1,000 PFU CHIKV SL15649 in the footpad. At 7 or 14 $\mathrm{dpi}$, mouse splenocytes were isolated and incubated with individual CHIKV 18-mer peptides overlapping by 10 amino acids and 1 e5 cells were incubated on IFN $\gamma$ ELISpot plates. At $48 \mathrm{~h}$ post incubation, ELISpot plates were washed and analyzed for spot formation. (A) Splenocytes from three mice were pooled and incubated with each individual CHIKV 18-mer in the CHIKV peptidome. Peptide numbers for reactive samples are indicated. (B) IFN $\gamma$ - eliciting peptides from (A) were repeated by ELISpot for two additional animals infected for 7 or 14 days. "LOD" indicates limit of detection.

HA tag for detection. The fusion construct was generated by overlapping PCR and cloned into shuttle plasmids that allowed recombineering into a MCMV Smith strain bacterial artificial chromosome and recombination into an E1A/E3 deleted AdV genome (Figure 2B). MCMV and AdV were reconstituted, and the insert was confirmed by sequencing. Western blotting for the 
TABLE 1 | CHIKV-specific immunoreactive peptides in C57BL/6 mice.

\begin{tabular}{|c|c|c|}
\hline 18-mer peptide sequence & Peptide \# & CHIKV protein \\
\hline MSDRKYHCVCPMRSAEDP & 10 & $\mathrm{nsP1}$ \\
\hline VYAVHAPTSLYHQAIKGV & 20 & $\mathrm{nsP1}$ \\
\hline HLKGKLSFTCRCDTWSC & 34 & nsP1 \\
\hline TCRCDTWSCEGYWKRI & 35 & $\mathrm{nsP1}$ \\
\hline SCEGYWKRITMSPGLYG & 36 & nsP1 \\
\hline LNQRIVVNGRTQRNTNTM & 46 & nsP1 \\
\hline GRTQRNTNTMKNYLLPVV & 47 & nsP1 \\
\hline TMKNYLLPVVAQAFSKWA & 48 & nsP1 \\
\hline CCLWAFKKQKTHTVYKRP & 53 & $\mathrm{nsP1}$ \\
\hline QKTHTVYKRPDTQSIQKV & 54 & nsP1 \\
\hline RTTNEYNKPIVVDTTGST & 109 & nsP2 \\
\hline VTWVAPLGVRGADYTYNL & 149 & nsP2 \\
\hline CVLGRKFRSSRALKPPCV & 160 & nsP2 \\
\hline PGGVCKAVYKKWPESFKN & 171 & nsP3 \\
\hline KQHAYHAPSIRSAVPSPF & 255 & nsP4 \\
\hline SIRSAVPSPFQNTLQNVL & 256 & nsP4 \\
\hline ELPTLDSAVFNVECFKKF & 260 & $\mathrm{nsP} 4$ \\
\hline GYYNWHHGAVQYSGGRFT & 332 & Capsid \\
\hline KPGDSGRPIFDNKGRWA & 335 & Capsid \\
\hline DNFNVYKATRPYLAHCPD & 350 & E2 \\
\hline GETLTVGFTDSRKISHSC & 363 & E2 \\
\hline VPKARNPTVTYGKNQVIM & 383 & E2 \\
\hline MCMCARRRCITPYELTPG & 398 & E2 \\
\hline PYSQAPSGFKYWLKERGA & 439 & E1 \\
\hline CAVHSMTNAVTIREAEIE & 451 & E1 \\
\hline KDHIVNYPASHTTLGVQD & 458 & E1 \\
\hline
\end{tabular}

Splenocytes from C57BL/6 mice infected with CHIKV were stimulated with CHIKV-specific 18-mer overlapping peptides, and IFN $\gamma$ production was measured by ELISpot assays. Consistent immunoreactive peptides are reported, and peptides that elicited the strongest IFN $\gamma$ responses are in bold lettering.

HA tag in lysates from mouse fibroblasts infected with each of the vaccine vectors confirmed the presence of the fusion protein expression for both constructs (Figure 2C). CHKVf5 was the expected size in AdV CHKVf5-infected cells (about $42 \mathrm{kDa}$ ). In the case of MCMV-CHKVf5, CHKVf5 is expressed as an in-frame C-terminal fusion onto IE2, and the IE2-CHKVf5 protein was detected at about $85 \mathrm{kDa}$.

\section{Immunogenicity and Efficacy Assessment of MCMV and AdV CHKVf5 Vaccine Vectors}

To evaluate vaccine immunogenicity, mice were vaccinated once with either MCMV CHKVf5, wild type MCMV lacking the CHKVf5 insert, or PBS by intraperitoneal injection $(n=$ 10/group). Separate groups of 10 mice per group were vaccinated i.m. in the left quadriceps muscle with AdV-CHKVf5 or AdVcontrol. The vaccine groupings and schedule are depicted in Figure 3A. MCMV vectored vaccines elicit robust $\mathrm{CD}^{+} \mathrm{T}$ cell responses by $6-8$ weeks post vaccination $(31,38)$. Adenovirus vaccine-induced $\mathrm{CD}^{+} \mathrm{T}$ cell responses peak between 10 and 14 days post vaccination (39). At 8 weeks post MCMV vaccination or 2 weeks post $\mathrm{AdV}$ vaccination, splenocytes were isolated from two mice per group for IFN $\gamma$ ELISpot assays. Splenocytes were incubated with peptides encoded by CHKVf5 (peptides 47, 256, 260, 416, and 451), the immunodominant peptides for the MCMV proteins M45 and IE3, or stimulated with PMA/Ionomycin (Figure 3B). Splenocytes from animals receiving MCMV CHKVf5 and AdV CHKVf5 developed IFN $\gamma$ responses to stimulation with nsP4 peptide 260 and E1 peptide 451. Splenocytes from mice receiving AdV-CHKVf5 also developed moderate IFN $\gamma$ responses to stimulation with nsp4 peptide 255. All MCMV-vaccinated mice, but not those receiving $\mathrm{AdV}$, responded to MCMV-specific peptides M45 and IE3.

The remaining animals were challenged with 1,000 PFU CHIKV SL15649 s.c. in the right footpad, and four mice per group were sacrificed at $3 \mathrm{dpi}$ or $28 \mathrm{dpi}$ to measure immunogencity and antiviral efficacy. Twenty-eight days after challenge, IFN $\gamma$ ELISpots were performed on the splenocytes from all vaccine groups (Figure 3C). While control mice challenged with CHIKV developed IFN $\gamma$ responses to CHIKV peptides, CHKf5-vaccined mice had a higher frequency of responding cells.

After CHIKV challenge, footpad swelling was monitored from 3 to $16 \mathrm{dpi}$. Interestingly, the CHKVf5-vaccinated mice had significantly increased footpad swelling at $3 \mathrm{dpi}$ compared to controls (Figure 3D). However, serum viremia and tissue viral loads were not affected by CHKVf5 vaccination (Figures 3E,F). Similarly, there were no significant differences in ankle tissue viral loads at $28 \mathrm{dpi}$ (Figure 3G). These data are largely consistent with studies that showed that $\mathrm{T}$ cells do not reduce viral load in the CHIKV footpad infection model $(22,23)$.

\section{CHKVf5 Vaccines Induced Protective Responses in Mice Challenged Intramuscularly}

In general, s.c. footpad CHIKV infection quickly replicates to high titers in the ankle, which promotes viral replication and dissemination in a manner that T cells may not be able to control. To test whether the route of infection influences $T$ cell vaccine efficacy, we inoculated mice with 1,000 PFU by three different infection routes (footpad, intramuscular into the calf muscle, or subcutaneous in the calf) in unvaccinated mice and monitored footpad swelling and viral tissue distribution (Figure 4). Only animals inoculated in the footpad developed swelling in the ipsilateral footpad and ankle (Figure 4A). Similarly, only animals inoculated via the footpad route developed measurable viremia at 3 dpi (Figure 4B). Infectious virus was isolated from footpad-infected animals in both ipsilateral and contralateral ankles and calf muscles (Figures 4C-F). Animals inoculated intramuscularly in the right calf had the most consistent and highest levels of virus in the ipsilateral calf at $5 \mathrm{dpi}$ and detectable virus in the ipsilateral ankle, while virus isolation from the contralateral ankle was highly variable. Animals inoculated s.c. in the right calf had detectable virus in the ipsilateral ankle, but levels in the ipsilateral calf and contralateral ankle were variable with no virus detectable in the contralateral calf muscle.

Since the i.m. infection group had consistent viral titers in the ipsilateral calf and ankle, we chose to vaccinate mice with 
A

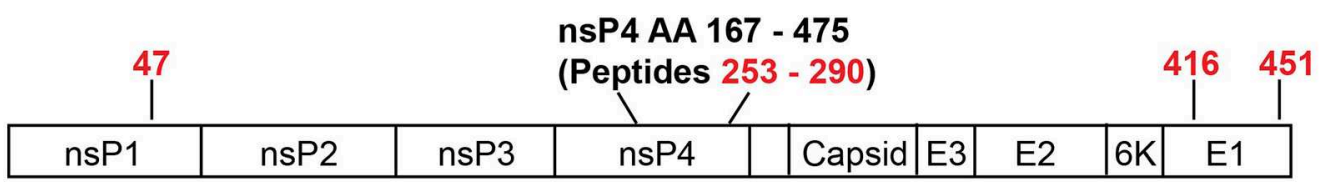

B

CHKVf5: $\quad$ peptide 451 GG peptide 416 GG nsP4 AA 167-475 GG peptide 47 1 HA

MCMV CHKVf5:

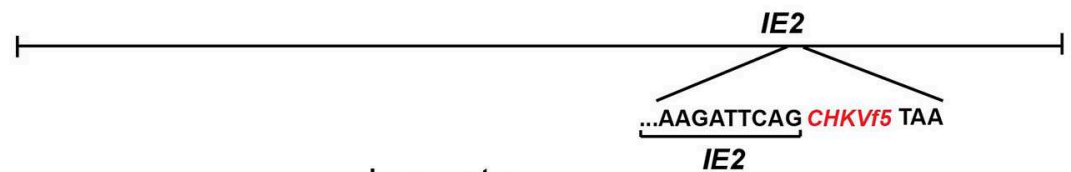

AdV CHKVf5:

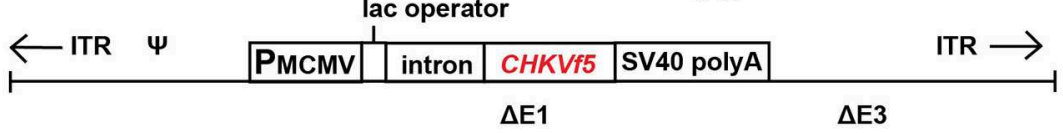

C

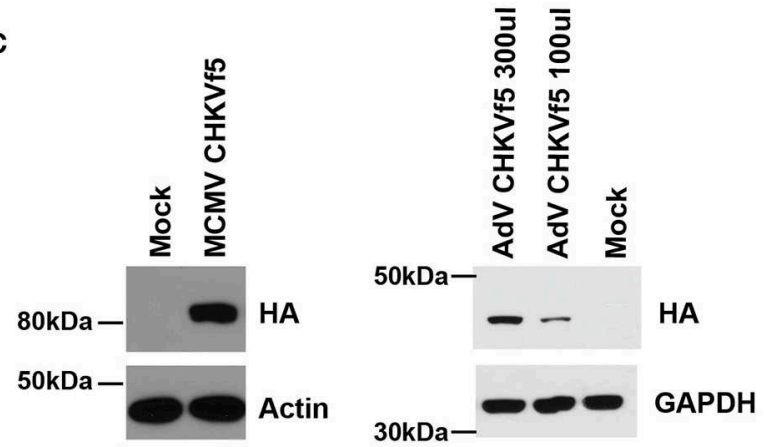

FIGURE 2 | MCMV and AdV vaccine vector expression of the CHKVf5 fusion gene. (A) Shown is the genomic position of the CHIKV peptides contained in CHIKVf5. (B) The CHIKVf5 fusion gene contains amino acid sequences for peptide 47, 416, and 451 as well as a 308 amino acid portion of nsp4, separated by 2 Gly residues. A C $\mathrm{C}^{\prime}$ terminal HA epitope (8 amino acids) was added for detection purposes. The CHKVf5 fusion gene was inserted into MCMV as a C-terminal fusion with IE2 and into a replication defective adenovirus 5 vector (deleted of E1 and E3). (C) Recombinant MCMV and AdV expressing CHKVf5 vectors were tested for HA expression in transduced NIH 3T3 cells. Cell lysates were analyzed at 1 dpi for HA and the loading controls actin or GAPDH.

CHKVf5 vaccines and challenge i.m. Mice were vaccinated with MCMV and AdV CHKVf5 or control vaccines as described above. A second group of mice received a primary vaccination with MCMV-CHKVf5 or the MCMV control vaccine, and at 8 weeks post prime these animals were boosted with AdV CHKVf5 or AdV control vaccine, respectively (Figure 5A). Prior to challenge with $\mathrm{CHIKV}, \mathrm{T}$ cell responses were measured in splenocytes from two animals per group by IFN $\gamma$ ELISpot assays. While splenocytes from AdV-CHKVf5 vaccinated mice produced higher levels of IFN $\gamma$ expressing T cells in response to CHIKV peptide stimulation compared to the MCMV vaccine platform, $\mathrm{T}$ cell response levels were highest for the prime boost approach (Figure 5B). Since two of the peptides included in the CHIKVf5 are derived from E1, we measured neutralizing antibody levels in the serum from mice vaccinated by the different regimens using standard plaque reduction neutralization titer (PRNT) assays. Sera from uninfected, unvaccinated animals was used as a negative control, and immune sera as well as a potent neutralizing monoclonal antibody (4N12) were used as positive controls for PRNT assays (11). Serum from all the CHKVf5 vaccine groups failed to neutralize CHIKV, suggesting that the CHIKVf5 vaccine does not elicit infection neutralizing nor enhancing antibodies (Figure 5C).

Seven mice from each vaccine group were challenged by i.m. calf injection with $10^{4} \mathrm{pfu}$ of CHIKV. At $5 \mathrm{dpi}$, mice were euthanized and tissues were collected for virological and immunological assessments. Infectious viral titers in the ipsilateral ankle and calf muscle were determined by limiting dilution plaque assays from tissue homogenates (Figures 5D,E). Though there was no statistically significant reduction in virus load in the ipsilateral ankle, there was a significant reduction in infectious virus in the ipsilateral calf from all of the CHIKVf5 vaccine groups (MCMV, AdV, and prime/boost) relative to the appropriate vaccine controls. This finding indicates that the vaccine dramatically reduces viral loads in the calf muscle, but not the ankle tissues.

\section{$\mathrm{CD}^{+}$and $\mathrm{CD}^{+}{ }^{+} \mathrm{T}$ Cells Mediate Protection by the CHKVf5 Vaccine}

Since neutralizing antibodies were not detected in the vaccinated animals at the time of challenge, we determined whether protection elicited by the CHIKVf5 vaccine is mediated by the 


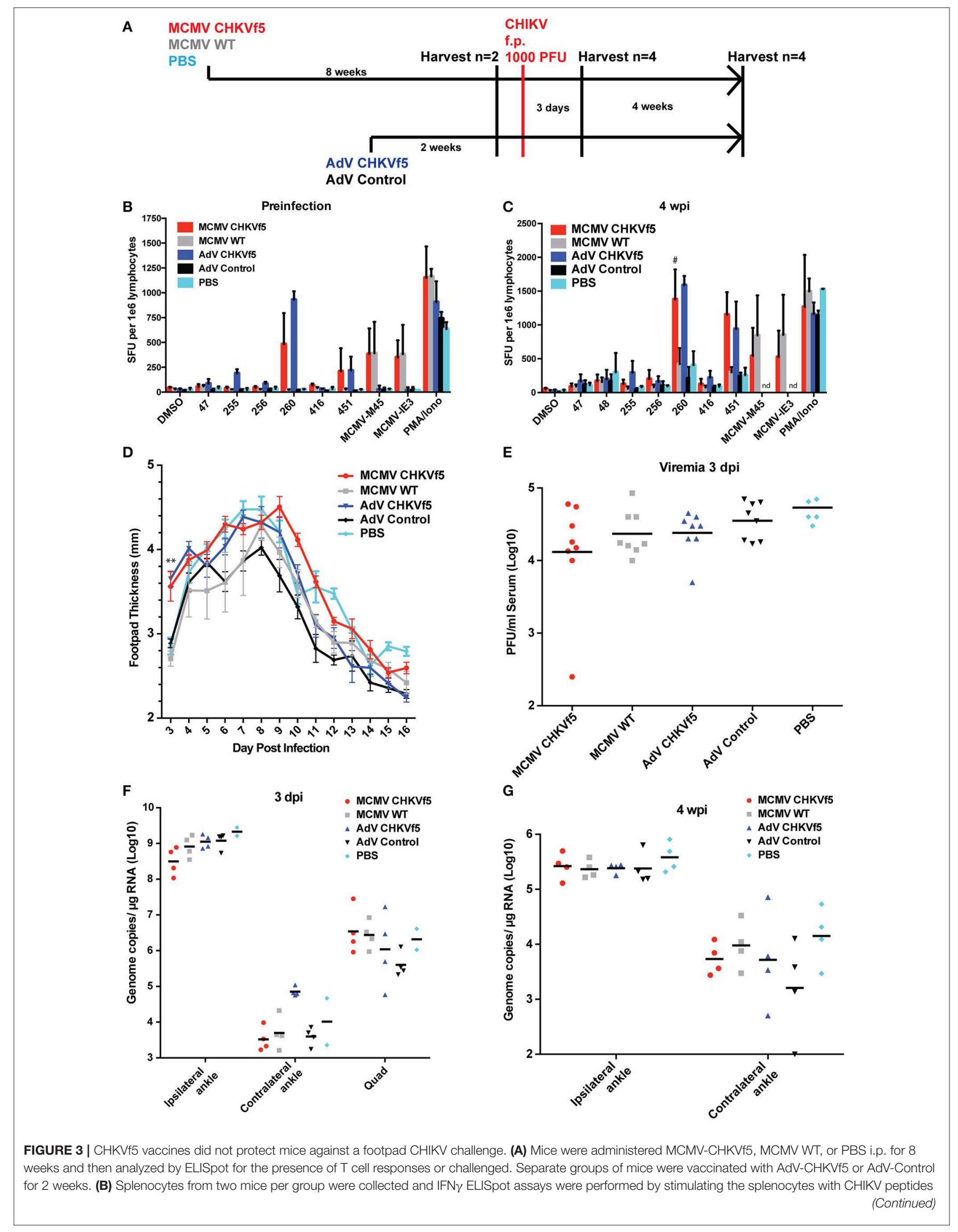


FIGURE 3 | incorporated in the CHKVf5 fusion gene. (C) IFN $\gamma$ ELISpot assay performed using splenocytes from mice vaccinated with the indicated vaccine and challenged with CHIKV SL15649 in the footpad ("\#” indicates too numerous to count; "nd" indicates not done). (D) Footpad thickness was measured using calipers from 3 to 16 dpi. (E) At 3 dpi, mice were bled and their serum was titered by limiting dilution plaque assay on confluent monolayers of Vero cells. (F) At 3 dpi, viral RNA extracted from ipsilateral and contralateral ankles and ipsilateral quadriceps was quantified by qRT-PCR. (G) At 4 wpi, viral RNA was extracted from ipsilateral and contralateral ankles and viral RNA levels were measured by qRT-PCR.

A

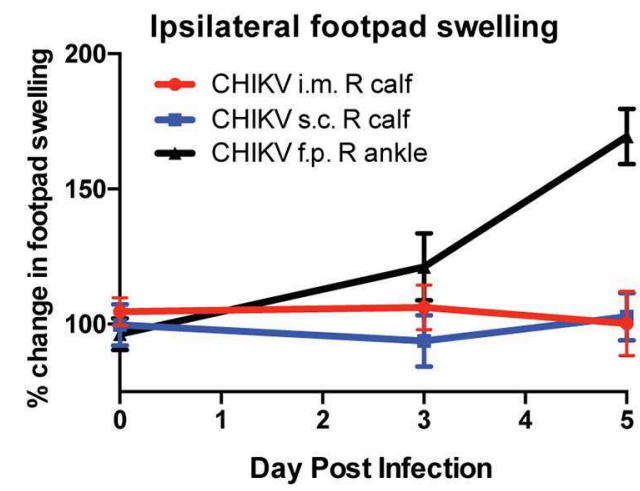

C

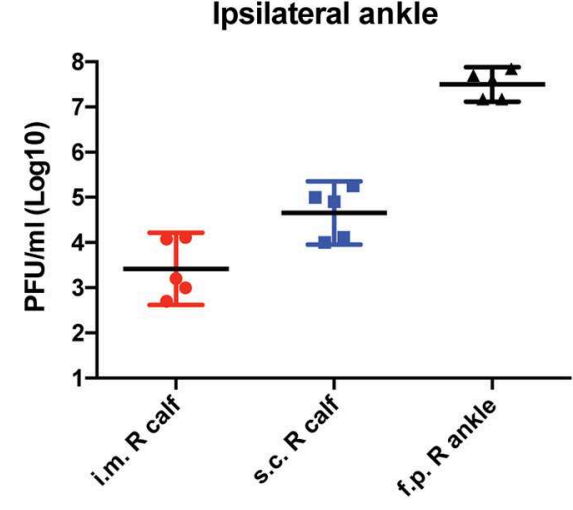

E

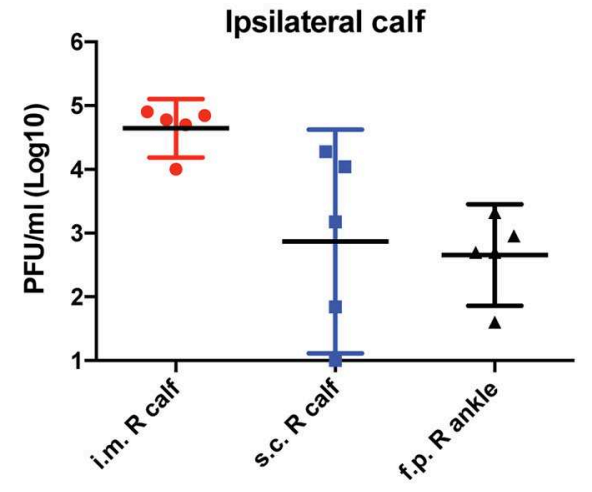

B

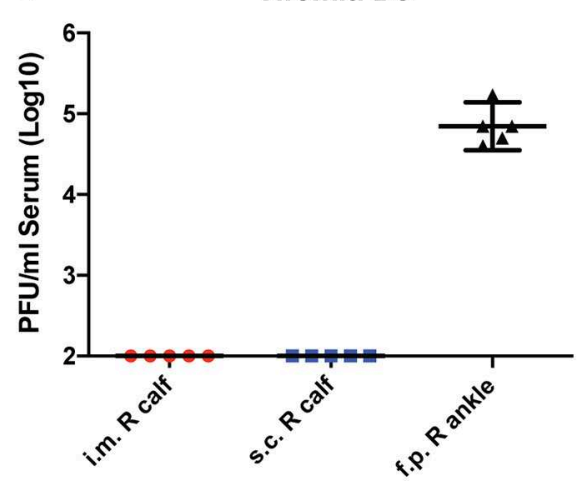

D Contralateral ankle
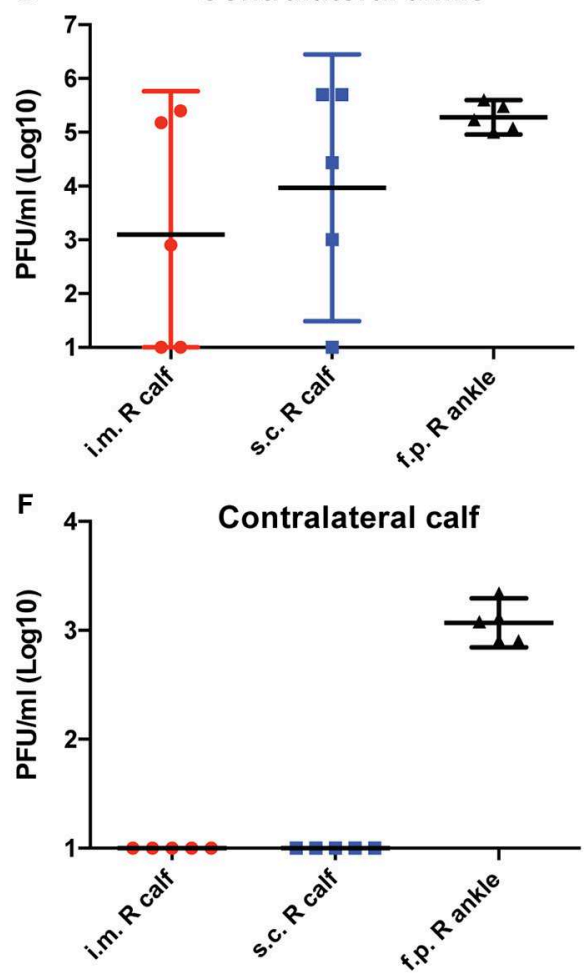

FIGURE 4 | C57BL/6 mice were infected with CHIKV by three different routes, and their footpad swelling and tissue viral distributions are compared. C57BL/6 mice were infected with 1,000 PFU CHIKV SL15649 intramuscularly in the right calf (i.m. R calf), subcutaneously in the skin of the right calf (s.c. right calf), or in the right leg footpad (f.p.). (A) Footpad swelling measurements were taken at 0, 3, and 5 dpi using calipers. (B) Serum from CHIKV-infected mice was isolated at 3 dpi, and viremia was measured by limiting dilution plaque assay on confluent monolayers of Vero cells. (C-F) At 5 dpi, mice were sacrificed and whole tissues were dissected and homogenized in $1 \mathrm{ml}$ cell culture media. Infectious viral levels in the ankle and calf muscle tissue homogenate were measured by limiting dilution plaque assay on confluent monolayers of Vero cells $(n=5)$.

induction of protective $\mathrm{T}$ cell responses by $\mathrm{T}$ cell depletion experiments in CHIKVf5 prime/boost vaccinated animals. At 14 days post boost ( 2 days before challenge), animals were infused with depleting antibodies targeting $\mathrm{CD} 4^{+}$and/or $\mathrm{CD} 8^{+} \mathrm{T}$ cells (Figure 6A). To confirm effective and specific $\mathrm{T}$ cell subset depletion, at $5 \mathrm{dpi}$ splenocytes isolated from three mice per 


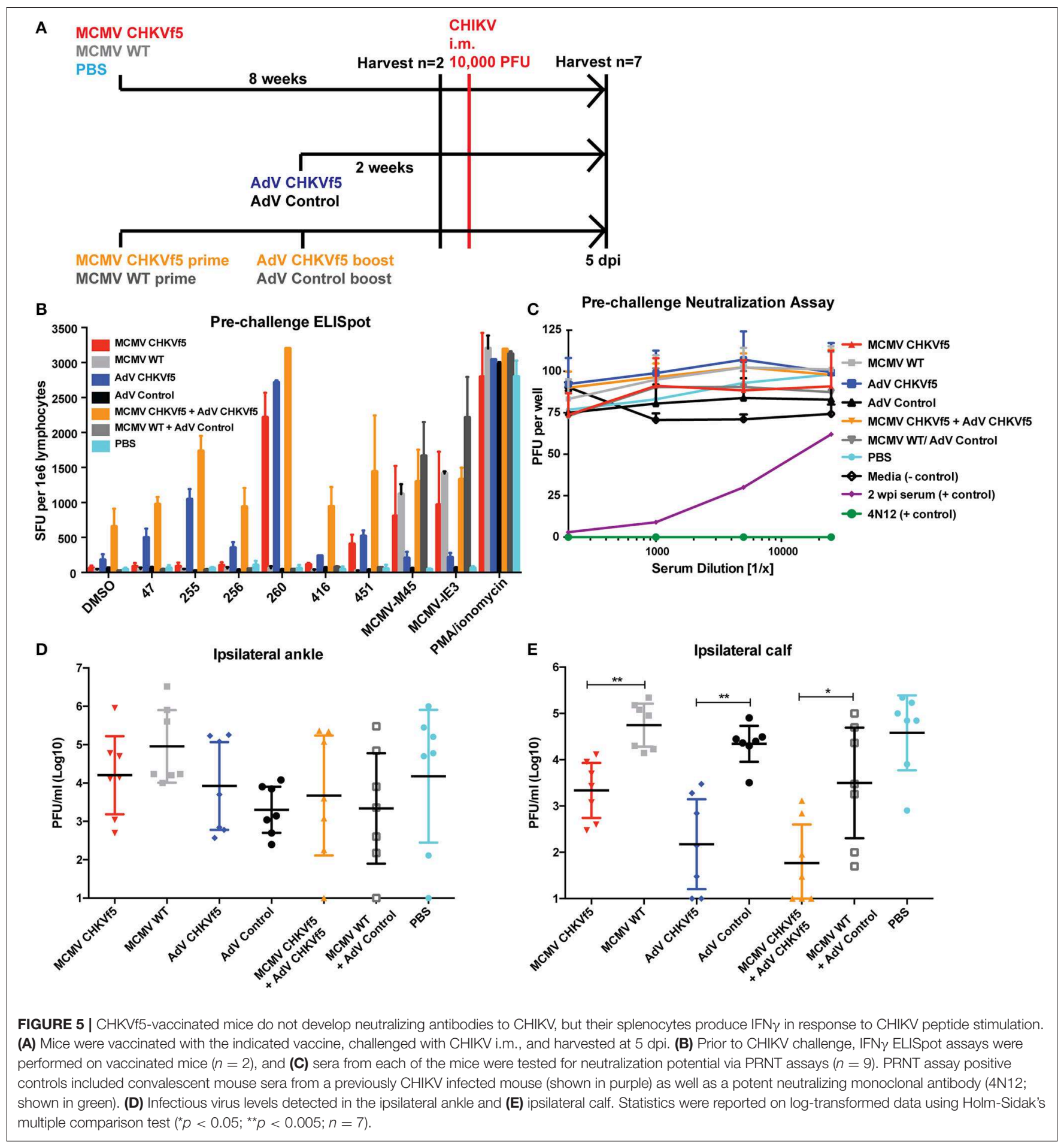

group were collected and analyzed by flow cytometry. As shown in Figure S1, depletion of specific T cell subpopulations (CD4 and/or CD8) were appropriately depleted to levels of $>95 \%$. At 5 days post challenge, CHKVf5-vaccinated mice that were untreated or those receiving control rat IgG or $\mathrm{CD} 4^{+} \mathrm{T}$ cell depleting antibodies had significantly reduced levels of infectious CHIKV present in the calf muscle relative to animals that received the control vaccine. These groups were not significantly different from each other suggesting that $\mathrm{CD}^{+}{ }^{+} \mathrm{T}$ cells alone do not play a major role in CHIKVf5-mediated protection. However, depletion of $\mathrm{CD}^{+} \mathrm{T}$ cells increased levels of infectious CHIKV present in the calf, which was enhanced in mice depleted for both $\mathrm{CD}^{+}$and $\mathrm{CD} 8^{+} \mathrm{T}$ cells. This finding indicates that while $\mathrm{CD} 8^{+}$ $\mathrm{T}$ cells are required for vaccine-mediated protection against 


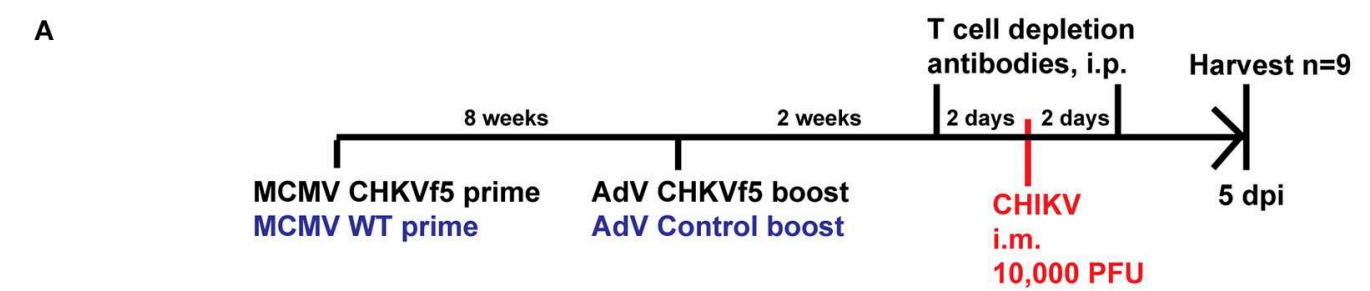

B

Ipsilateral ankle
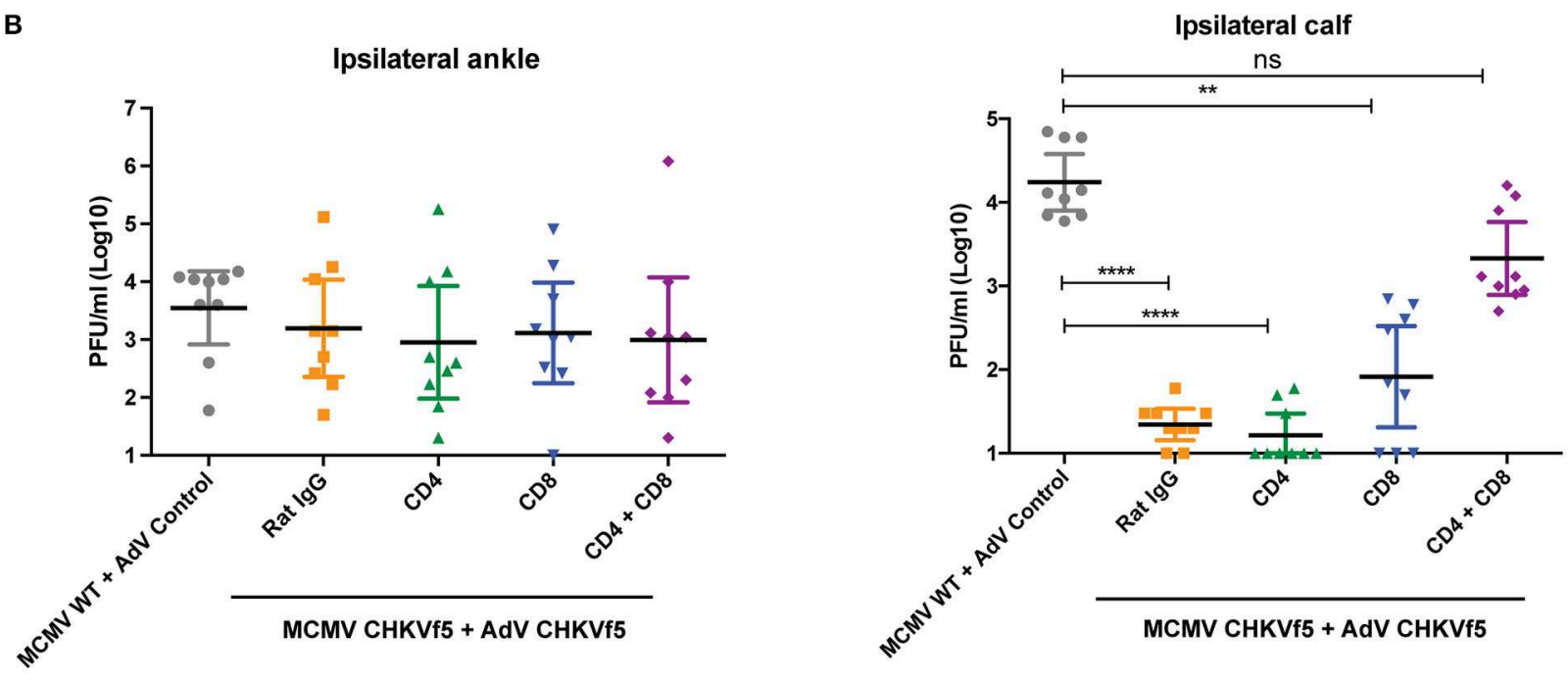

C

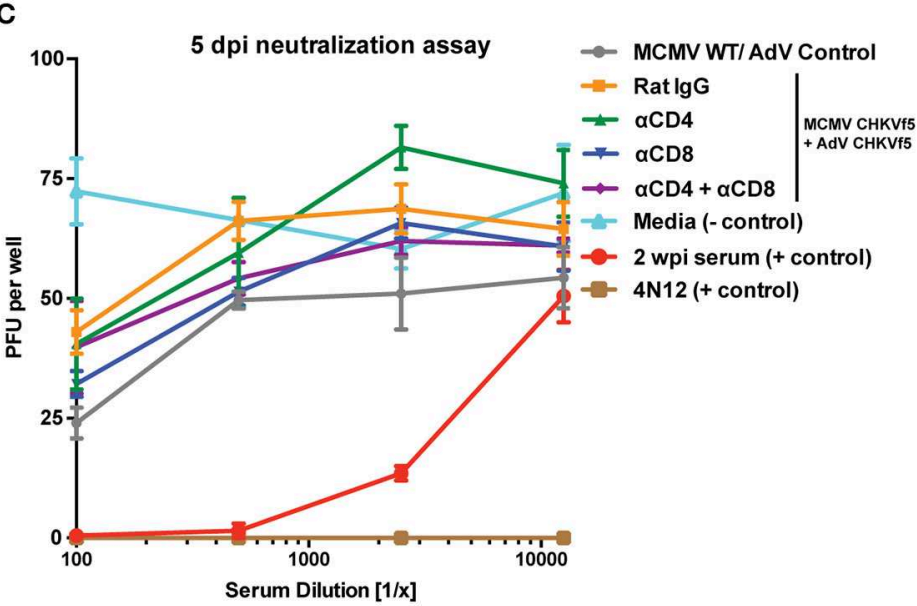

D

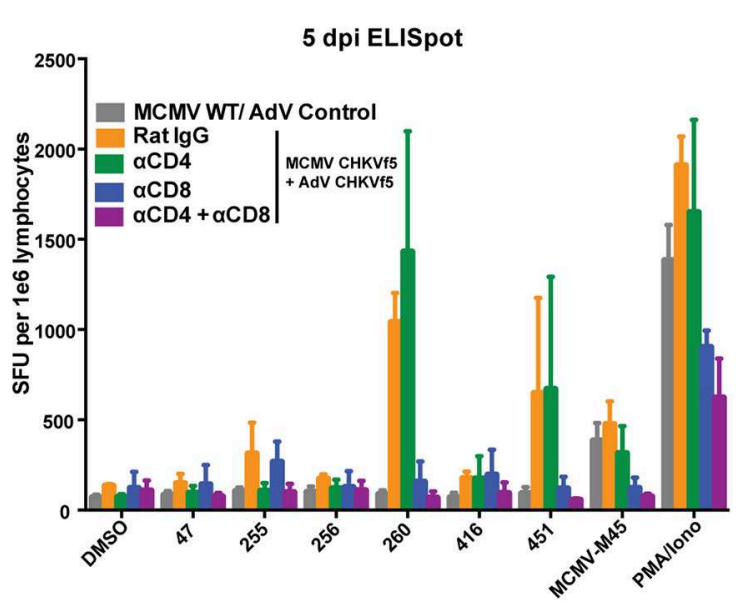

FIGURE 6 | Combined $\mathrm{CD}^{+}$and CD4 ${ }^{+} \mathrm{T}$ cell depletion reverses the protective effect of the CHKVf5 vaccine. (A) Mice vaccinated with MCMV-CHKVf5 and boosted with AdV-CHKVf5, or control vectors were treated with $300 \mu \mathrm{g}$ rat isotype control, anti-CD4, anti-CD8, or anti-CD4 plus anti-CD8 depleting antibodies at 2 days prior to challenge. Mice were infected i.m. with 10,000 PFU CHIKV SL15649, and (B) ankle and calf tissue viral loads were measured by limiting dilution plaque assays. Statistical analysis was performed on log-transformed data using Dunn's multiple comparison test ${ }^{\star \star *} p<0.005 ;{ }^{\star \star \star \star} p<0.0001 ; n=9$ ). (C) Neutralization assays were performed using mouse serum isolated at 5 dpi. (D) Splenocytes from vaccinated mice were collected and stimulated with CHIKV peptides on ELISpot plates. The results of the ELISpot assay are reported $(n=4)$.

CHIKV i.m. challenge, $\mathrm{CD}^{+}$and $\mathrm{CD}^{+} \mathrm{T}$ cells cooperate to mediate protection in the calf muscle.

As expected, similar viral levels were detected in the ankles for all groups (Figure 6B). Data in Figure 6C demonstrate that CHIKV neutralizing antibodies were not present in the vaccinated mice prior to CHIKV challenge. In addition, splenocytes from the various groups were analyzed by peptide ELISpot assay, shown in Figure 6D. These data show that in 


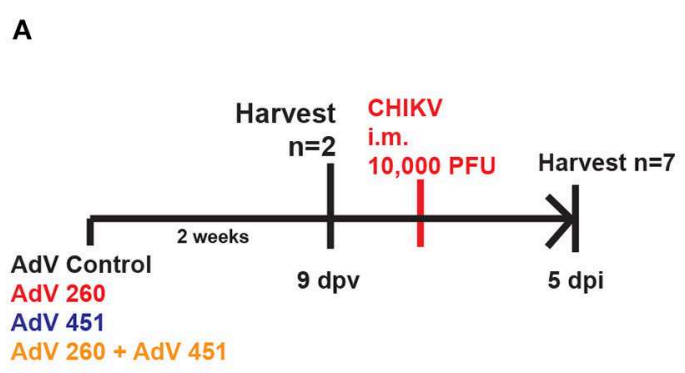

C

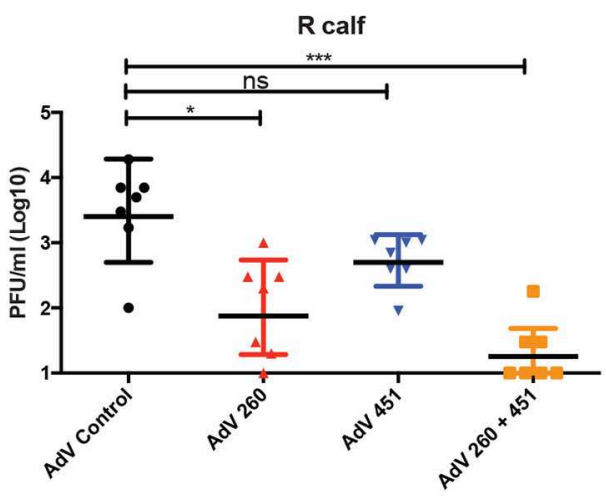

B

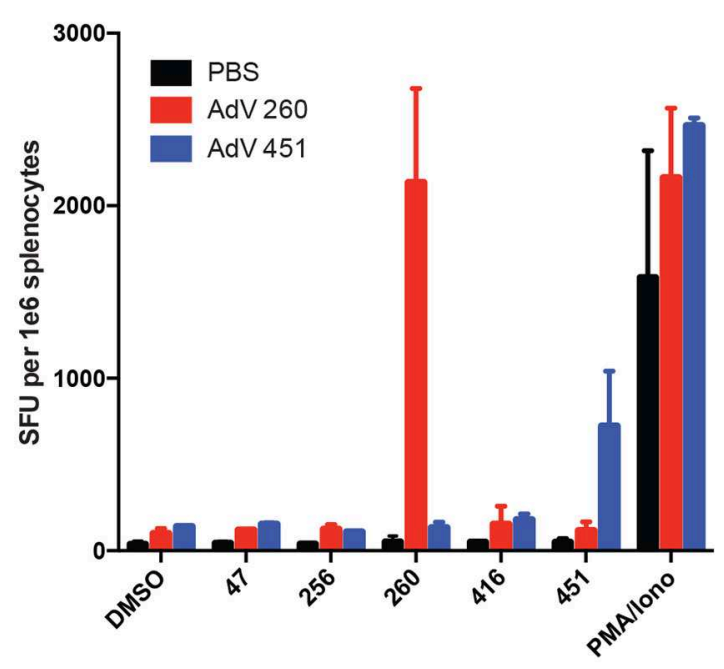

D

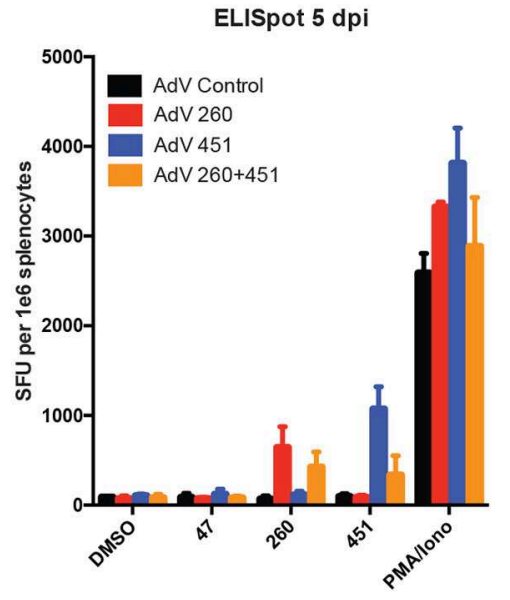

FIGURE 7 | AdV-260 and AdV-451 vaccination elicits T cells responses and protects mice from CHIKV in ipsilateral calf. (A) Mice were vaccinated with AdV-260 and/or AdV-451 or PBS (i.m.). Mice were infected i.m. with 10,000 PFU CHIKV SL15649. (B) Prior to CHIKV challenge, IFN $\gamma$ ELISpot assays were performed on a subset of vaccinated mice $(n=2)$. (C) Virus was measured in the ipsilateral footpad by qRT-PCR at 5 dpi. Statistical analysis was performed on log-transformed data using Dunnett's multiple comparison test (ns, not significant; ${ }^{\star} p<0.05 ;{ }^{\star \star \star} p<0.0005 ; n=7$ ). (D) At 5 dpi, IFN $\gamma$ ELISpot assays were performed on splentocytes from a subset of vaccinated mice $(n=3)$.

vivo depletion of $\mathrm{CD} 4^{+} \mathrm{T}$ cells eliminated IFN $\gamma$ responses for peptide 255, but responses for peptides 260 and 451 were only blocked by depletion of $\mathrm{CD}^{+} \mathrm{T}$ cells. These data indicate that maximum muscle tissue protective immunity elicited by the CHKVf5 vaccine is mediated by both $\mathrm{CD}_{4}^{+}$and $\mathrm{CD}^{+} \mathrm{T}$ cells that act in concert to reduce viral loads in the muscle tissue.

\section{CD8-Specific AdV 260 and AdV 451 Reduce CHIKV Disease}

Since $\mathrm{CD} 8^{+} \mathrm{T}$ cells were essential for the protective effects of the CHKVf5 vaccine, we generated adenoviruses individually expressing the CD8-specific CHIKV peptides 260 and 451. CHIKV-specific $\mathrm{T}$ cell responses in mice vaccinated with AdVControl, AdV-260, or AdV-451, demonstrated appropriate IFN $\gamma$ responses against peptides 260 and 451 (Figures 7A,B). An additional cohort of these vaccinated mice were challenged with CHIKV i.m. AdV 260 vaccination alone resulted in significantly reduced virus in the ipsilateral calf, but AdV451 vaccination, while trending lower than controls, was not statistically significantly different than mice vaccinated with a control AdV (Figure 7C). Mice vaccinated with both AdV-260 and AdV-451 had a highly significant decrease in infectious virus compared to controls. The vaccinated and challenged mice also showed vaccine-specific $\mathrm{T}$ cell responses after 260 and 451 peptide stimulation (Figure 7D). Therefore, the $\mathrm{CD} 8^{+} \mathrm{T}$ cells elicited after vaccination with adenovirus-delivered peptides 260 and 451 are protective against i.m. CHIKV challenge.

We next tested efficacy of disease protection for the AdV260 and AdV-451 vaccines using the f.p. CHIKV challenge model as outlined in Figure 8A. Footpad swelling at both of the biphasic peaks occurring at day 4 and 8 post infection was significantly reduced in mice vaccinated and boosted with 


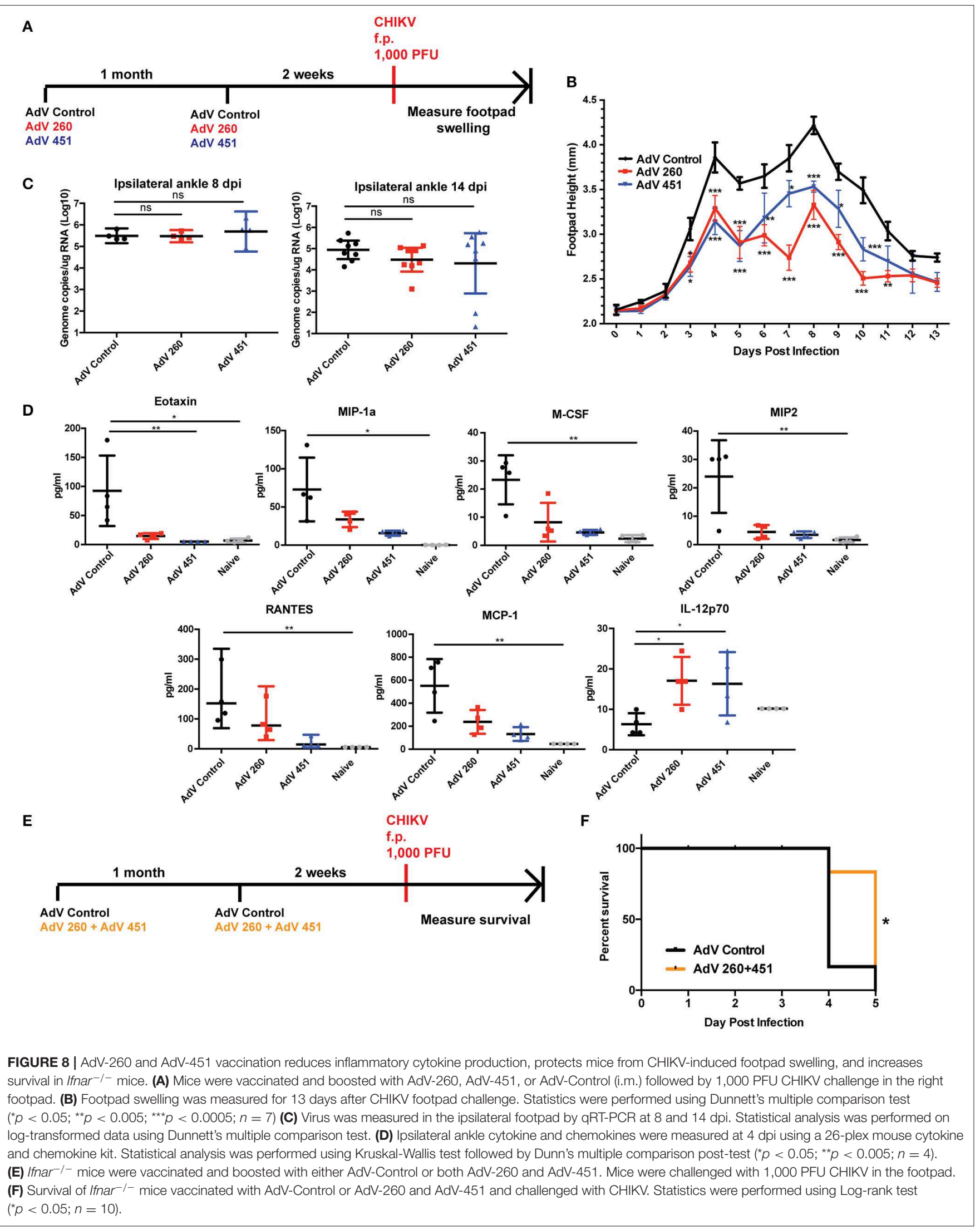


AdV-260 or AdV-451 compared to mice receiving the control AdV (Figure 8B), despite having no statistically significant effect on CHIKV viral RNA loads in the ipsilateral ankles at 8 and 14 dpi (Figure 8C). Due to this response, we hypothesized that preexisting antiviral $\mathrm{CD} 8^{+} \mathrm{T}$ cells may be associated with differential expression of proinflammatory cytokines and chemokines in the CHIKV-infected ankles. We therefore performed a multiplex cytokine assay using ipsilateral ankle homogenates harvested at 4 dpi from mice vaccinated with AdV control, AdV 260, and AdV 451. From this we observed significantly higher levels of Eotaxin in challenged AdV Control mice relative to Adv 260, Adv 451, and naïve animals that are unchallenged and unvaccinated (Figure 8D). Levels of MIP-1 $\alpha$, M-CSF, MIP2, MCP-1, and RANTES were also elevated in AdV control relative to naïve but not AdV 260 or AdV 451 groups. Interestingly, IL-12p70 was significantly increased in the AdV 260 and AdV 451 groups compared to AdV Control, suggesting a positive role for IL-12p70 in controlling the CHIKV-induced inflammation after vaccination.

We next tested whether vaccination with AdV-260 and AdV-451 could improve survival in a lethal CHIKV mouse model. Mice lacking the type I IFN receptor (Ifnar1 ${ }^{-/-}$) are extremely susceptible to CHIKV and succumb to virus infection 3-4 dpi (40), and represent a highly stringent survival model. Mice receiving AdV-260 and AdV-451 exhibited a 1-day advantage in survival over the AdV-Control group (Figures 8E,F). Therefore, the $\mathrm{CD}^{+}{ }^{+} \mathrm{T}$ cell vaccine could protect immunocompetent mice from footpad swelling after CHIKV f.p. challenge, and the vaccine provided significant survival advantage in Ifnar $1^{-/-}$mice.

\section{DISCUSSION}

While the development of neutralizing antibodies is a clear immunological correlate of protection for CHIKV, it was unknown what role $\mathrm{T}$ cells play in protection against $\mathrm{CHIKV}$ infection and disease. In the current study, we mapped the $\mathrm{T}$ cell responses to $\mathrm{CHIKV}$ in C57BL/6 mice using an overlapping CHIKV peptide library in order to identify potential CHIKV targets for development of a $\mathrm{T}$ cell vaccine. During this $\mathrm{T}$ cell profiling experiment, we identified 26 unique peptide sequences that elicited significant IFN $\gamma$ responses in splenocytes obtained from CHIKV-infected C57BL/6 mice. Based upon this information, we constructed a fusion polyprotein that contained the amino acid sequence for a number of these positive $\mathrm{CD} 4^{+}$ and $\mathrm{CD}^{+}$restricted peptides. This $\mathrm{CHKVf5}$ fusion gene was inserted into two different $\mathrm{T}$ cell promoting vaccine platforms including MCMV and AdV. Vaccinated mice developed robust $\mathrm{T}$ cell responses directed against the transgene construct that were amplified following challenge with CHIKV. Vaccination prior to footpad inoculation resulted in a dramatic increase in footpad swelling at $3 \mathrm{dpi}$. We attribute this to preformed anti-CHIKV CD4 ${ }^{+} \mathrm{T}$ cells. While the CHKVf5 vaccine did not protect against high ankle viral loads following challenge, it did significantly reduce viral loads in the calf muscle when i.m. challenged with CHIKV.
Two crucial findings indicate that the CHKVf5 vaccine elicits protection through T cells. First, depletion of $\mathrm{CD} 4^{+}$and $\mathrm{CD} 8^{+}$ $\mathrm{T}$ cells at 2 days before challenge from vaccinated mice negated the protective efficacy of the vaccine against i.m. challenge by restoring viral loads to levels observed in vaccine controls and non-vaccinated mice. It appears that both $\mathrm{T}$ cell subtypes contribute to immune efficacy since depletion of either $\mathrm{CD}^{+}$ or $\mathrm{CD}^{+} \mathrm{T}$ cells failed to fully restore CHIKV tissue load to control levels. However, depletion of $\mathrm{CD}^{+} \mathrm{T}$ cells significantly reduced the ability of mice to control virus indicating a dominant role for these cells. We presume that $\mathrm{CD} 4^{+} \mathrm{T}$ cell help is required for full efficacy but these cells specifically enhance CHIKV inflammatory joint disease. Second, the CHKVf5 vaccine does not contain any known CHIKV neutralizing domains. As such, we did not detect neutralizing antibodies against CHIKV in any of the vaccinated mice, and the generation of antibody responses against $\mathrm{CHIKV}$ following challenge developed with normal kinetics and amplitude when compared to controls indicating that there was no amnestic-type response. Together, these data demonstrate that the CHKVf5 vaccine constructs elicit robust $\mathrm{T}$ cell responses that protected against $\mathrm{CHIKV}$ in muscle tissues. Finally, we showed that vaccination with adenoviruses containing $\mathrm{CD} 8^{+} \mathrm{T}$ cell epitopes did not decrease joint tissue viral loads after footpad challenge, but it reduced footpad swelling and inflammation following CHIKV challenge. In addition, the $\mathrm{CD} 8^{+} \mathrm{T}$ cell vaccine provided enhanced survival for Ifnar $1^{-/-}$mice.

$\mathrm{T}$ cell responses directed against $\mathrm{CHIKV}$ have been reported in humans during both the acute and chronic phases of infection. During the acute phase, there is a mobilization and amplification of activated CD8 ${ }^{+} \mathrm{T}$ cells, followed by $\mathrm{CD} 4^{+} \mathrm{T}$ cells (41). Following the acute phase, patients who recovered from CHIKV and patients with chronic CHIKV-induced arthritis both had roughly equal frequencies of CHIKV-specific IFN $\gamma$-producing $\mathrm{T}$ cells (42). There is also evidence that $\mathrm{T}$ cells can enter CHIKV infected joint tissues in humans. In a synovial biopsy of a patient with chronic CHIKV-induced arthritis, activated (HLA-DR ${ }^{+}$) $\mathrm{CD}^{+}{ }^{+} \mathrm{T}$ cells were identified as a major cellular infiltrate, but oddly, $\mathrm{CD}^{+} \mathrm{T}$ cells were rarely found (1). CHIKV RNA and antigen have been detected in joint synovial biopsies and muscle tissue $(1,43)$, which is suggestive of viral persistence in the joints and muscle. Though it is not known whether $\mathrm{T}$ cells protect against CHIKV in humans, our data would suggest that the presence of effective antiviral $\mathrm{CD}^{+} \mathrm{T}$ cells may promote viral clearance in the muscle tissue and control joint inflammation.

We showed that vaccinated animals had a significant reduction of CHIKV titers in the calf muscle. The tissue-specific protection is reminiscent of the study with RRV, where protection by $\mathrm{CD}^{+}{ }^{+} \mathrm{T}$ cells was observed in the muscle tissue during RRV infection (26), but $\mathrm{CD}^{+} \mathrm{T}$ cells failed to reduce viral loads in the ankle tissues. Similarly, we found that CHKVf5-elicited T cells and peptide 260 and 451-elicited T cells were unable to significantly reduce viral burden in the ankles. Similar tissuetype targeting occurs following SINV infection, where $\mathrm{T}$ cells are important for viral clearance in the brain and spinal cord (27). In addition, $\mathrm{CD}^{+}{ }^{+} \mathrm{T}$ cells were important for protection mediated by a live-attenuated vaccine for VEEV (28). Together 
these studies demonstrate the importance of $\mathrm{T}$ cells in alphavirus clearance from infected tissues.

Interestingly, we found that $\mathrm{T}$ cell responses elicited by CHIKVf5 were more frequent and directed against different epitopes when compared to those observed following CHIKV infection. For example, splenocytes from CHIKV infected mice had high frequencies of IFN $\gamma$ responses to peptides 47-48, 256, 350,439 , and 451 . While $\mathrm{T}$ cell responses against peptides 350 and 439 were robust, the $\mathrm{CHKVf5}$ did not contain these because it was designed prior to us determining whether these were $\mathrm{CD}^{-}$or CD ${ }^{-}$specific. Future T cell vaccine constructs would most likely add these epitopes as they may impact protection. Since peptides 47, 256, and 451 were included in the CHKVf5 fusion gene, we expected that vaccinated mice would primarily induce responses to those epitopes. However, peptide 260 and 451 elicited the highest frequency of IFN $\gamma^{+}$T cells in splenocytes from CHKVf5 vaccinated mice indicating that vaccine-induced responses were skewed toward infection-associated, non-dominant epitopes. Thus, one could argue that the protection elicited by the CHKVf5 vaccine may be due to this skewing of the immune response and higher frequencies of responding $\mathrm{T}$ cells. Similarly, while both MCMV- and AdV-CHKVf5 vaccines elicited strong T cell responses, the breadth of the responses was vaccine vectordependent. The AdV-CHKVf5 vaccine directed responses against peptides 47, 255, 256, 260, and 451, while MCMV-CHKVf5 mainly directed T cells against 260 and 451. Prime-boost with both vectors increased the frequency and breadth of responses. Adenovirus vectors elicit potent effector and central memory $\mathrm{CD}^{+}{ }^{+} \mathrm{T}$ cells (44) whereas MCMV vectors, in general, elicit longlasting effector memory $\mathrm{T}$ cells to vaccine antigens fused to the C-terminus of the IE2 gene $(31,38,45)$. Together, the MCMV prime/AdV boost may offer advantages in induction of a diverse $\mathrm{T}$ cell memory response to CHIKV epitopes resulting in a more protective phenotype.

Neutralizing antibodies are an important correlate of protection for CHIKV, and it would be essential for a prophylactic CHIKV vaccine to induce neutralizing antibody responses to protect from CHIKV acquisition. The data presented here show that a CD8-directed $\mathrm{T}$ cell component in a prophylactic vaccine would be beneficial. This type of vaccine could also be used

\section{REFERENCES}

1. Hoarau JJ, Jaffar Bandjee MC, Krejbich Trotot P, Das T, Li-Pat-Yuen G, Dassa B, et al. Persistent chronic inflammation and infection by Chikungunya arthritogenic alphavirus in spite of a robust host immune response. J Immunol. (2010) 184:5914-27. doi: 10.4049/jimmunol.09 00255

2. Gérardin P, Fianu A, Malvy D, Mussard C, Boussaïd K, Rollot $\mathrm{O}$, et al. Perceived morbidity and community burden after a Chikungunya outbreak: the TELECHIK survey, a populationbased cohort study. BMC Med. (2011) 9:5. doi: 10.1186/17417015-9-5

3. Schilte C, Staikowsky F, Staikovsky F, Couderc T, Madec Y, Carpentier $\mathrm{F}$, et al. Chikungunya virus-associated long-term arthralgia: a 36-month prospective longitudinal study. PLoS Negl Trop Dis. (2013) 7:e2137. doi: 10.1371/journal.pntd.00 02137 to prophylactically boost existing immunity and/or skew the responses toward additional epitopes for increased protection against CHIKV acquisition. This approach could be effective for eliminating $\mathrm{CHIKV}$-induced myalgia and joint swelling in infected patients. Therefore, future studies will examine the effects of therapeutic $\mathrm{T}$ cell vaccines against CHIKV persistence and disease.

\section{DATA AVAILABILITY STATEMENT}

This manuscript contains previously unpublished data and materials that are available upon request.

\section{ETHICS STATEMENT}

The animal study was reviewed and approved by Oregon National Primate Research Center (ONPRC) Institutional Animal Care and Use Committee.

\section{AUTHOR CONTRIBUTIONS}

RB, NH, TA, ID, CK, JP, MD, PS, IM, and DS performed the experiments. RB, TM, MH, VD, DC, and DS wrote and edited the manuscript. All authors contributed to discussions about the results and their impact.

\section{FUNDING}

This work was supported by grants from the National Institutes of Health 1U19AI109680-01 and R41AI138964-01.

\section{SUPPLEMENTARY MATERIAL}

The Supplementary Material for this article can be found online at: https://www.frontiersin.org/articles/10.3389/fimmu. 2019.02563/full\#supplementary-material

Figure S1 | CD4 ${ }^{+}$and $\mathrm{CD}^{+}{ }^{+} \mathrm{T}$ cell depletions were confirmed in splenocytes of infected mice. Levels of $\mathrm{CD}^{+}$and $\mathrm{CD}^{+}{ }^{+} \mathrm{T}$ cells were measured in splenocytes from mice that received Rat isotype IgG, anti-CD4, or anti-CD8 antibodies by flow cytometry.
4. Couturier E, Guillemin F, Mura M, Léon L, Virion JM, Letort MJ, et al. Impaired quality of life after chikungunya virus infection: a 2-year followup study. Rheumatology. (2012) 51:1315-22. doi: 10.1093/rheumatology/ kes015

5. Powers AM, Logue $\mathrm{CH}$. Changing patterns of chikungunya virus: reemergence of a zoonotic arbovirus. J Gen Virol. (2007) 88:2363-77. doi: 10.1099/vir.0.82858-0

6. Weaver SC. Arrival of chikungunya virus in the new world: prospects for spread and impact on public health. PLoS Negl Trop Dis. (2014) 8:e2921. doi: 10.1371/journal.pntd.0002921

7. Weaver SC, Forrester NL. Chikungunya: evolutionary history and recent epidemic spread. Antiviral Res. (2015) 120:32-9. doi: 10.1016/j.antiviral.2015.04.016

8. Couderc T, Khandoudi N, Grandadam M, Visse C, Gangneux $\mathrm{N}$, Bagot S, et al. Prophylaxis and therapy for Chikungunya virus infection. J Infect Dis. (2009) 200:516-23. doi: 10.1086/ 600381 
9. Hawman DW, Stoermer KA, Montgomery SA, Pal P, Oko L, Diamond MS, et al. Chronic joint disease caused by persistent Chikungunya virus infection is controlled by the adaptive immune response. J Virol. (2013) 87:13878-88. doi: 10.1128/JVI.02666-13

10. Pal P, Fox JM, Hawman DW, Huang YJ, Messaoudi I, Kreklywich C, et al. Chikungunya viruses that escape monoclonal antibody therapy are clinically attenuated, stable, and not purified in mosquitoes. J Virol. (2014) 88:8213-26. doi: 10.1128/JVI.01032-14

11. Broeckel R, Fox JM, Haese N, Kreklywich CN, Sukulpovi-Petty S, Legasse $\mathrm{A}$, et al. Therapeutic administration of a recombinant human monoclonal antibody reduces the severity of chikungunya virus disease in rhesus macaques. PLoS Negl Trop Dis. (2017) 11:e0005637. doi: 10.1371/journal.pntd.0005637

12. Chang LJ, Dowd KA, Mendoza FH, Saunders JG, Sitar S, Plummer SH, et al. Safety and tolerability of chikungunya virus-like particle vaccine in healthy adults: a phase 1 dose-escalation trial. Lancet. (2014) 384:2046-52. doi: 10.1016/S0140-6736(14)61185-5

13. Hallengärd D, Kakoulidou M, Lulla A, Kümmerer BM, Johansson DX, Mutso $\mathrm{M}$, et al. Novel attenuated Chikungunya vaccine candidates elicit protective immunity in C57BL/6 mice. J Virol. (2014) 88:2858-66. doi: 10.1128/JVI.03453-13

14. López-Camacho C, Kim YC, Blight J, Lazaro Moreli M, Montoya-Diaz E, Huiskonen JT, et al. Assessment of immunogenicity and neutralisation efficacy of viral-vectored vaccines against chikungunya virus. Viruses. (2019) 11:E322. doi: 10.3390/v11040322

15. Reisinger EC, Tschismarov R, Beubler E, Wiedermann U, Firbas C, Loebermann $\mathrm{M}$, et al. Immunogenicity, safety, and tolerability of the measles-vectored chikungunya virus vaccine MV-CHIK: a double-blind, randomised, placebo-controlled and active-controlled phase 2 trial. Lancet. (2019) 392:2718-27. doi: 10.1016/S0140-6736(18)32488-7

16. Rezza G, Weaver SC. Chikungunya as a paradigm for emerging viral diseases: evaluating disease impact and hurdles to vaccine development. PLoS Negl Trop Dis. (2019) 13:e0006919. doi: 10.1371/journal.pntd.00 06919

17. Plante K, Wang E, Partidos CD, Weger J, Gorchakov R, Tsetsarkin K, et al. Novel chikungunya vaccine candidate with an IRES-based attenuation and host range alteration mechanism. PLoS Pathog. (2011) 7:e1002142. doi: 10.1371/journal.ppat.1002142

18. Chu H, Das SC, Fuchs JF, Suresh M, Weaver SC, Stinchcomb DT, et al. Deciphering the protective role of adaptive immunity to CHIKV/IRES a novel candidate vaccine against Chikungunya in the A129 mouse model. Vaccine. (2013) 31:3353-60. doi: 10.1016/j.vaccine.2013.05.059

19. Roy CJ, Adams AP, Wang E, Plante K, Gorchakov R, Seymour RL, et al. Chikungunya vaccine candidate is highly attenuated and protects nonhuman primates against telemetrically monitored disease following a single dose. $J$ Infect Dis. (2014) 209:1891-9. doi: 10.1093/infdis/jiu014

20. Weger-Lucarelli J, Chu H, Aliota MT, Partidos CD, Osorio JE. A novel MVA vectored Chikungunya virus vaccine elicits protective immunity in mice. PLoS Negl Trop Dis. (2014) 8:e2970. doi: 10.1371/journal.pntd.0002970

21. Morrison TE, Oko L, Montgomery SA, Whitmore AC, Lotstein AR, Gunn $\mathrm{BM}$, et al. A mouse model of chikungunya virus-induced musculoskeletal inflammatory disease: evidence of arthritis, tenosynovitis, myositis, and persistence. Am J Pathol. (2011) 178:32-40. doi: 10.1016/j.ajpath.2010.11.018

22. Teo TH, Lum FM, Claser C, Lulla V, Lulla A, Merits A, et al. A pathogenic role for $\mathrm{CD}^{+} \mathrm{T}$ cells during Chikungunya virus infection in mice. J Immunol. (2013) 190:259-69. doi: 10.4049/jimmunol.1202177

23. Teo TH, Chan YH, Lee WW, Lum FM, Amrun SN, Her Z, et al. Fingolimod treatment abrogates chikungunya virus-induced arthralgia. Sci Transl Med. (2017) 9:eaal1333. doi: 10.1126/scitranslmed.aal1333

24. Miner JJ, Cook LE, Hong JP, Smith AM, Richner JM, Shimak RM, et al. Therapy with CTLA4-Ig and an antiviral monoclonal antibody controls chikungunya virus arthritis. Sci Transl Med. (2017) 9:eaah3438. doi: 10.1126/scitranslmed.aah3438

25. Poo YS, Rudd PA, Gardner J, Wilson JA, Larcher T, Colle MA, et al. Multiple immune factors are involved in controlling acute and chronic chikungunya virus infection. PLoS Negl Trop Dis. (2014) 8:e3354. doi: 10.1371/journal.pntd.0003354
26. Burrack KS, Montgomery SA, Homann D, Morrison TE. CD ${ }^{+} \mathrm{T}$ cells control Ross River virus infection in musculoskeletal tissues of infected mice. J Immunol. (2015) 194:678-89. doi: 10.4049/jimmunol.14 01833

27. Binder GK, Griffin DE. Interferon-gamma-mediated site-specific clearance of alphavirus from CNS neurons. Science. (2001) 293:303-6. doi: 10.1126/science.1059742

28. Yun NE, Peng BH, Bertke AS, Borisevich V, Smith JK, Smith JN, et al. $\mathrm{CD}^{+} \mathrm{T}$ cells provide protection against acute lethal encephalitis caused by Venezuelan equine encephalitis virus. Vaccine. (2009) 27:4064-73. doi: 10.1016/j.vaccine.2009.04.015

29. Matthews DA, Cummings D, Evelegh C, Graham FL, Prevec L. Development and use of a 293 cell line expressing lac repressor for the rescue of recombinant adenoviruses expressing high levels of rabies virus glycoprotein. J Gen Virol. (1999) 80:345-53. doi: 10.1099/0022-1317-80-2-345

30. Messerle M, Crnkovic I, Hammerschmidt W, Ziegler H, Koszinowski $\mathrm{UH}$. Cloning and mutagenesis of a herpesvirus genome as an infectious bacterial artificial chromosome. Proc Natl Acad Sci USA. (1997) 94:14759-63. doi: 10.1073/pnas.94.26.14759

31. Tsuda Y, Caposio P, Parkins CJ, Botto S, Messaoudi I, Cicin-Sain L, et al. A replicating cytomegalovirus-based vaccine encoding a single Ebola virus nucleoprotein CTL epitope confers protection against Ebola virus. PLoS Negl Trop Dis. (2011) 5:e1275. doi: 10.1371/journal.pntd.0001275

32. Warming S, Costantino N, Court DL, Jenkins NA, Copeland NG. Simple and highly efficient BAC recombineering using galK selection. Nucleic Acids Res. (2005) 33:e36. doi: 10.1093/nar/gni035

33. Paredes AM, Yu D. Human cytomegalovirus: bacterial artificial chromosome (BAC) cloning and genetic manipulation. Curr Protoc Microbiol Chapter. (2012) 14:Unit14E.4. doi: 10.1002/9780471729259.mc14e $04 \mathrm{~s} 24$

34. Safronetz D, Hegde NR, Ebihara H, Denton M, Kobinger GP, St Jeor S, et al. Adenovirus vectors expressing hantavirus proteins protect hamsters against lethal challenge with andes virus. J Virol. (2009) 83:7285-95. doi: 10.1128/JVI.00373-09

35. Pelliccia M, Andreozzi P, Paulose J, D’Alicarnasso M, Cagno V, Donalisio $\mathrm{M}$, et al. Additives for vaccine storage to improve thermal stability of adenoviruses from hours to months. Nat Commun. (2016) 7:13520. doi: $10.1038 /$ ncomms 13520

36. Muthumani K, Lankaraman KM, Laddy DJ, Sundaram SG, Chung CW, Sako E, et al. Immunogenicity of novel consensus-based DNA vaccines against Chikungunya virus. Vaccine. (2008) 26:5128-34. doi: 10.1016/j.vaccine.2008.03.060

37. Pratheek BM, Suryawanshi AR, Chattopadhyay S. In silico analysis of MHC-I restricted epitopes of Chikungunya virus proteins: implication in understanding anti-CHIKV CD8(+) $\mathrm{T}$ cell response and advancement of epitope based immunotherapy for CHIKV infection. Infect Genet Evol. (2015) 31:118-26. doi: 10.1016/j.meegid.2015.01.017

38. Karrer U, Wagner M, Sierro S, Oxenius A, Hengel H, Dumrese $\mathrm{T}$, et al. Expansion of protective $\mathrm{CD}^{+}$T-cell responses driven by recombinant cytomegaloviruses. J Virol. (2004) 78:2255-64. doi: 10.1128/JVI.78.5.2255-2264.2004

39. Yang TC, Dayball K, Wan YH, Bramson J. Detailed analysis of the CD8 ${ }^{+} \mathrm{T}$ cell response following adenovirus vaccination. J Virol. (2003) 77:13407-11. doi: 10.1128/JVI.77.24.13407-13411.2003

40. Couderc T, Chretien F, Schilte C, Disson O, Brigitte M, Guivel-Benhassine F, et al. A mouse model for Chikungunya: young age and inefficient type-I interferon signaling are risk factors for severe disease. PLoS Pathog. (2008) 4:e29. doi: 10.1371/journal.ppat.0040029

41. Wauquier N, Becquart P, Nkoghe D, Padilla C, Ndjoyi-Mbiguino A, Leroy EM. The acute phase of Chikungunya virus infection in humans is associated with strong innate immunity and T CD8 cell activation. J Infect Dis. (2011) 204:115-23. doi: 10.1093/infdis/jiq006

42. Hoarau JJ, Gay F, Pellé O, Samri A, Jaffar-Bandjee MC, Gasque P, et al. Identical strength of the $\mathrm{T}$ cell responses against $\mathrm{E} 2, \mathrm{nsP} 1$ and capsid CHIKV proteins in recovered and chronic patients after the epidemics of 2005-2006 in La Reunion Island. PLoS ONE. (2013) 8:e84695. doi: 10.1371/journal.pone.0084695 
43. Ozden S, Huerre M, Riviere JP, Coffey LL, Afonso PV, Mouly V, et al. Human muscle satellite cells as targets of Chikungunya virus infection. PLoS ONE. (2007) 2:e527. doi: 10.1371/journal.pone.00 00527

44. Tatsis N, Fitzgerald JC, Reyes-Sandoval A, Harris-McCoy KC, Hensley SE, Zhou D, et al. Adenoviral vectors persist in vivo and maintain activated CD8 ${ }^{+}$ T cells: implications for their use as vaccines. Blood. (2007) 110:1916-23. doi: 10.1182/blood-2007-02-062117

45. Farrington LA, Smith TA, Grey F, Hill AB, Snyder CM. Competition for antigen at the level of the APC is a major determinant of immunodominance during memory inflation in murine cytomegalovirus infection. J Immunol. (2013) 190:3410-6. doi: 10.4049/jimmunol.1203151
Conflict of Interest: The authors declare that the research was conducted in the absence of any commercial or financial relationships that could be construed as a potential conflict of interest.

Copyright (c) 2019 Broeckel, Haese, Ando, Dmitriev, Kreklywich, Powers, Denton, Smith, Morrison, Heise, DeFilippis, Messaoudi, Curiel and Streblow. This is an open-access article distributed under the terms of the Creative Commons Attribution License (CC BY). The use, distribution or reproduction in other forums is permitted, provided the original author(s) and the copyright owner(s) are credited and that the original publication in this journal is cited, in accordance with accepted academic practice. No use, distribution or reproduction is permitted which does not comply with these terms. 